\title{
Analyzing structural variations along strike in a deep-water thrust belt
}

Yukitsugu Totake a,b,, Robert W. H. Butler a, Clare E. Bond a, Aznan Azizc

a Geology and Petroleum Geology, School of Geosciences, University of Aberdeen, Kings College, Aberdeen AB24 3UE, UK

b Technical Resources Unit, Technical Division, INPEX CORPORATION, Tokyo 1076332, Japan

${ }^{c}$ Resource Exploration Department, PETRONAS, Kuala Lumpur 50088, Malaysia

${ }^{*}$ Corresponding author: yukitsugu.totake@inpex.co.jp (Y. Totake) 
- Fault heave changes along strike in a deep-water thrust belt, offshore Malaysia.

- Multiple heave maxima on the main thrusts suggest merger of fault segments.

- Fault linkage sites exhibiting local heave minima concur with distributed strain on small imbricate thrusts and tight folds.

- Fault linkage and displacement kinematics are affected by adjacent structures across strike.

- A fold-thrust structure may be better characterized as a part of kinematically linked 3D system. 


\section{Abstract}

2

3 We characterize a deep-water fold-thrust arrays imaged by a high-resolution 3D

4 seismic dataset in the offshore NW Borneo, Malaysia, to understand the kinematics

5 behind spatial arrangement of structural variations throughout the fold-thrust system.

6 The seismic volume used covers two sub-parallel fold trains associated with a series

7 of fore-thrusts and back-thrusts. We measured fault heave, shortening value, fold

8 geometries (forelimb dip, interlimb angle and crest depth) along strike in individual fold

9 trains. Heave plot on strike projection allows to identify individual thrust segments

10 showing semi-elliptical to triangular to bimodal patterns, and linkages of these

11 segments. The linkage sites are marked by local minima in cumulative heave. These

12 local heave minima are compensated by additional structures, such as small imbricate

13 thrusts and tight folds indicated by large forelimb dip and small interlimb angle.

14 Complementary profiles of the shortening amount for the two fold trains result in

15 smoother gradient of total shortening across the structures. We interpret this reflects

16 kinematic interaction between two fold-thrust trains. This type of along-strike variation

17 analysis provides comprehensive understanding of a fold-thrust system and may

18 provide an interpretative strategy for inferring the presence of complex multiple faults

19 in less well-imaged parts of seismic volumes. 


\section{Introduction}

Fold-thrust belts have long been investigated in various settings, from orogenic belts to gravitational failure on passive margins, especially for the hydrocarbon exploration. In these endeavors, many interpretational strategies have been adopted in the application of structural geology. Since at least the 1980s geoscientists have developed diverse kinematic models (see Groshong et al., 2012; Brandes and Tanner, 2013 for recent reviews) and non-kinematic techniques (e.g. Williams and Chapman, 1983; Groshong and Epard, 1994) to illustrate thrust-related folding. These approaches deal with the cross-sectional geometry essentially, whereas contractional structures vary the kinematics and structural geometry along strike (Figure 1). Detailed descriptions of such along-strike structural variations remain few on thrust systems.

This has led to our poor understanding of the deformation style and evolution of foldthrust structures in three dimensions. Aims of this contribution are 1) to provide descriptions of deep-water fold-thrust arrays imaged by a high-resolution 3D seismic dataset, and 2) to assess the kinematics underlying spatial arrangement of structural variations in the fold-thrust system.

Dahlstrom (1969) demonstrated that quantitative analysis of along-strike structural variations helps explain the kinematics of a fold-thrust array in the Alberta Front Range. Based on displacement changes along strike, he postulated that a thrust fault died out laterally and the displacement lost on the thrust was transferred to another so that net shortening is largely conserved along strike (Figure 2). Dahlstrom's work has developed into various attempts to characterize structural architectures transferring displacement among thrust faults (O'Keefe and Stearns, 1982; Sanderson and Spratt, 1992; Fermor, 1999), to investigate the evolution of fold-thrust systems through the 
propagation and linkage along strike (King and Yielding, 1984; Ellis and Dunlap, 1988; Nicol et al., 2002; Davis et al., 2005; Mazzoli et al., 2005), and to build geologically reasonable cross-sections throughout fold-thrust arrays (Watkins et al., 2017), with uses of variations in the shortening amount or displacement plotted on strike projections. But most studies depended on sparsely distributed data points. Few studies presented detailed characteristics of along-strike variations (Nicol et al., 2002; Davis et al., 2005). A small number of analogue experiments (Gardner and Spang, 1973; Liu and Dixon, 1991) and seismic-based studies (Higgins et al., 2009; Bergen and Shaw, 2010) have shown along-strike changes in shortening and displacement quantitatively and detailedly. The displacement distribution along strike and the kinematic linkage between thrust faults and folds are not fully resolved yet. It is mainly due to scarcity of geometrical constraints on thrust systems. Field studies suffer from the erosion removing thrust hangingwalls and the burial of footwalls beneath thrust sheets. Analogue experiments are no exception to the latter issue. Even where seismic data are available, complex seismic velocities compounded by deformation structure and repeated stratigraphy result in unclear seismic reflection images.

This contrasts with intensive studies on normal faults, where fault displacement patterns have been analyzed along strike and dip minutely in fields and with seismic datasets. Analyses of detailed displacement patterns along strike have brought significant insights into the development of fault linkage (Peacock and Sanderson, 1991; Childs et al., 1995; Dawers and Anders, 1995; Soliva and Benedicto, 2004; Giba et al., 2012), displacement-length scaling (Walsh and Watterson, 1991; Cowie and Scholz, 1992; Dawers et al., 1993; Schlische et al., 1996; Kim and Sanderson, 2005), and the fault growth history (Anders and Schlische, 1994; Cartwright et al., 1995; Jackson et al., 2002; Meyer et al., 2002; Walsh et al., 2003). Analogue experiments 
70 have examined these works with far more detail (Mansfield and Cartwright, 2001;

71 Bellahsen et al., 2003; Schlagenhauf et al., 2008; Wyrick et al., 2011). Advanced

72 knowledges for normal faults may help comprehend thrust fault systems further. But

73 we need more investigations to know how much both systems are comparable.

74 We describe imbricate thrusts developed through deep-water sandstone-shale 75 sequences in the offshore area of NW Borneo, Malaysia, using a high-resolution 3D seismic dataset acquired by the multi-azimuth technology. The best quality of this $3 \mathrm{D}$ seismic data provides good, three-dimensional constraints for structural geometry of thrust faults and related folds. We present along-strike variations in the fault displacement, fault dip, fold geometry and shortening amount at intervals of $250 \mathrm{~m}$ to $1 \mathrm{~km}$. Above all, the displacement variation is quantified using measurement of fault heave so that the measurement is readily made while avoiding influence of erroneous depth conversion. Using these quantified along-strike variations, we show that a single fold-thrust structure is a result of not only segment linkage along strike, but also interaction of folding and faulting, and interference with adjacent structures across strike. We provide a model accounting for spatial arrangement of structural complexity controlled by segment linkage.

\section{Geological setting}

90

The NW Borneo continental margin has been extensively explored for hydrocarbons since the 1950's (Scherer, 1980) (Figure 3a). Thanks to many industrial wells and seismic reflection surveys, the geology in this region has become clear, as

94 summarized by various authors (e.g. Petronas, 1999; Hutchison, 2005; Cullen, 2010). 
The NW Borneo continental margin is marked by regressive Middle Miocene to recent sandstone-shale successions, exceeding $11 \mathrm{~km}$ of thickness in some places (Lu and

97 Shipp, 2011) (Figure 3b, c). These Neogene sediments have been shed from the Borneo interior hinterland that experienced considerable uplift and erosion from the Early Miocene onward (Morley and Back, 2008; Hall, 2013). The Neogene coastal to shallow-marine sequences unconformably overlie the Upper Cretaceous to Early Miocene deep-water accretionary prism called Rajang-Crocker Group in the inboard area (Morley et al., 2003; Sapin et al., 2011). The Neogene hemi-pelagic strata onlap the pre-Early Miocene Dangerous Ground terrane in the NW Borneo Trough (Hinz et al., 1989; Hutchison, 2010) (Figure 3b, c).

The target in this study is a fold-thrust belt developed through the Neogene deepwater successions in the slope area (Figure 3a). It is $350 \mathrm{~km}$ long and $70 \mathrm{~km}$ wide, trending NE-SW adjacent to the NW Borneo Trough. This compressional province consists of five to seven trains of fault-propagation folds associated with NW-verging 109 thrusts (Hinz et al., 1989; Hesse et al., 2010) (Figure 3b, c). The thrust sheets are 110 assumed to be detached on over-pressured Early Miocene shale (Ingram et al., 2004).

111 The master detachment is estimated to lie at a depth of c. $4 \mathrm{~km}$ below seabed near 112 the toe thrust front and c. $10 \mathrm{~km}$ at the up-slope shelf break (Morley, 2007; Morley et 113 al., 2014). Folding and thrusting were initiated in the Late Miocene and have 114 propagated NW-ward over time (Franke et al., 2008; Sapin et al., 2013). The process 115 appears to continue today, as indicated by the seafloor deformation and GPS motion records (Simons et al., 2007). Note that the fold structures and their underlying thrusts

117 were not active in a strict sequence. Although the age of growth strata indicates a 118 general forward migration of deformation, structures were active in parallel. It is a 119 feature to which we shall return at the end of this paper. 
There are two end-member hypotheses as to the mechanism of the Neogene-torecent compression: crustal shortening driven by collisional plate tectonics (Hinz et al., 1989) and the gravitational failure analogous to that in the Niger Delta (Tan and Lamy, 1990; Hazebroek and Tan, 1993). Many workers argued that both mechanisms have

124 contributed, to varying degrees in terms of which is dominant (e.g. Ingram et al., 2004;

125 Franke et al., 2008; Morley et al., 2008, 2011; Hesse et al., 2009; Sapin et al., 2013). But, these debates do not affect our structural interpretation essentially.

\section{Database}

130

The database for this study consists of data from four boreholes tied into a 3D seismic survey of c. $830 \mathrm{~km}^{2}$ full-fold area (Figure 4). The seismic survey was acquired in 2012 using deep-towed dual-sensor broadband system of PGS GeoStreamer® and

134 multi-azimuth technology. Data recording in structurally complex areas were repeated along three sail-line orientations at $60^{\circ}$ to each other (Figure $4 \mathrm{a}$ ). The multi-azimuth datasets were processed using Kirchhoff pre-stack depth migration and were then stacked through multi-survey regularization and binning. In the processed data, spacing in both inlines and crosslines is $12.5 \mathrm{~m}$, sampling rate is $2 \mathrm{~ms}$, and the data record length is $7 \mathrm{~s}$. The vertical resolution of the data varies from c. $10 \mathrm{~m}$ near the

140 sediment surface to c. $30 \mathrm{~m}$ at the top of deformed successions considered here, 141 dropping to perhaps as much as $90 \mathrm{~m}$ at the base of these intervals. The seismic full142 fold volume is covered by seismic velocities that were finalized through five iterations 143 of velocity picking on $50 \mathrm{~m} \times 50 \mathrm{~m} \times 50 \mathrm{~m}(\mathrm{x}, \mathrm{y}$ and $\mathrm{z})$ grid with applications of isotropic 144 and anisotropic tomography. 


\section{Seismic interpretation}

The seismic data clearly display multi-layered reflectors of turbiditic sandstoneshale alternations deformed into fold-thrust structures (Figure 5). These sequences

151 interbed with seismically chaotic packages that denote cyclic occurrences of mass transport deposits, or MTDs (Algar et al., 2011) (Figure 5). A well shows that reflective packages on seismic images correspond to sand-dominant sequences and poorly

154 reflective intervals including MTDs are shale-dominant (Figure 6). Based on structural patterns of these excellent illuminations, we identified three tectonic sequences 156 (Figure 5b):

1) Pre-kinematic strata that show a constant stratigraphic thickness and are deformed by folds and thrusts. This unit is characterized by laterally continuous reflectors and extensive MTDs throughout the survey area. Deeper sections in thrust footwalls appear to thicken perhaps due to the drag along thrust faults.

2) Syn-kinematic strata that exhibit significant short-range changes in thickness. They thin toward anticline crests and show local onlaps within the strata and onto the pre-kinematic strata. Thrust faults cut the deeper section of the strata. Tilting angle of fold limbs decreases upward so that anticline shapes broaden at shallower depth. MTDs are not extensive as those in the pre-kinematic strata, they are distributed only on forelimbs. Extensional normal faults develop though the strata on anticline crests with minor offsets. 
173 Thrust faults are mappable from offsets in the section below the lower syn-kinematic 174 strata. However, the deeper section, including detachment layers and ramps, are not 175
3) Post-kinematic strata that drape underlying deformed strata with rather constant thickness. These strata are offset by a series of minor normal faults on anticline crests, like the syn-kinematic strata. imaged clearly.

We mapped eight regional stratigraphic markers defined at wells, seabed and horizon h8 to h2, over the seismic volume (Figure 5b, 6). These horizons interpreted are dated between Late Miocene to Quaternary based on biostratigraphic analysis (Figure 6). We also mapped horizon h1, a continuous reflector having a positive acoustic impedance at the base of the multi-layered pre-kinematic successions. This horizon is not penetrated by the wells within the seismic volume. The interval between the seabed and horizon $h 7$ is the post-kinematic, horizons $h 7$ to $h 4$ define the synkinematic, and below horizon h4 is the pre-kinematic strata (Figure 5b). Thrust faults were interpreted along dip sections at interval of 312.5 to $1250 \mathrm{~m}$ and checked for spatial continuities and structural relationships to other faults and horizons on arbitrary time slices. We depth-converted horizons and thrust faults interpreted using seismic velocities calibrated with borehole data.

The mapped seismic horizons are involved in three separate, sub-parallel trains of non-cylindrical conical fold with strike trending NS to NE-SW (Figure 7). We name these fold trains $\mathrm{A}, \mathrm{B}$ and $\mathrm{C}$ from west to east for convenience. They are mostly faultpropagation folds that are associated with underlying thrusts. Syn-kinematic horizon h7 produces relatively gentle fold shapes with the fold train B opening southward (Figure 7a), whereas pre-kinematic horizon h4 exhibits clear fold shapes cut by a 
194 series of thrusts (Figure 7b). Individual fold trains exhibit along-strike change in geometry that may be linked to the underlying thrust geometry.

\section{Methods}

199

200

We describe the fold trains $A$ and $B$ that are well covered by the seismic data, with 201 focus on structural variations along strike on top pre-kinematic strata, horizon $\mathrm{h} 4$, using 202 the elevation map and a series of seismic profiles. The fold train $C$ is not analyzed in 203 this study due to its limited extent within the seismic data coverage. We then compare 204 these observations with along-strike changes in measurements of structural 205 geometries and kinematics - fault heave, shortening value, fault dip, forelimb dip, 206 interlimb angle and fold crestal depth (Figure 8). All these measurements were made 207 in depth domain after performing depth conversion.

208 We use the fault heave as a proxy for fault displacement ( $h$ in Figure 8). This is to 209 demonstrate a practicality of the heave for analyzing displacement distribution along 210 traces of thrust faults in the seismic-based study. Unlike normal faults frequently 211 analyzed using throw, thrust faults are better described using heave as they incline at 212 low angles and their horizontal displacement components are significant. Use of the 213 heave is also advantageous in seismic studies; heave measurements are less 214 susceptible to the seismic depth conversion. We measured fault heaves at horizon h4, 215 on dip sections spaced every $250 \mathrm{~m}$. We note that these heave measurements are 216 sensitive to, not only fault displacements, but also fault dip angles. Relationship 217 between fault heaves, dip-separations and fault dips in our study area shows that ratio 218 of heave to dip-separation falls, down to near $50 \%$ at minimum, as the fault dip 
219 increases (Figure 9). This suggests that we need to analyze heave measurements 220 carefully when fault dip angles are large, as heaves become apparently diminished even with constant or increased fault displacements. We deal with this by examining 222 along-strike changes in the fault dip together when we evaluate heave profiles. 223 However, majority of our heave measurements (90\% of the measurements) are 224 associated with thrusts dipping $40^{\circ}$ or less (Figure 9). On these thrusts, heaves equal 225 more than $77 \%$ of dip-separations that roughly correspond to fault displacements on the dip sections. Most thrusts do not change their dips considerably throughout the study area. Thus, we argue that overall tendencies of our heave measurements along strike mostly represent those of lateral displacement patterns.

We calculated the shortening amount for the horizon h4, using the line-length balance (Dahlstrom, 1969) (Figure 8), on dip sections spaced at $1 \mathrm{~km}$ intervals along strike. We pinned these sections away from fold-thrust structures at hinge point of 232 synclines in thrust footwalls or place where the seismic marker becomes horizontal. 233 Shortening values are obtained by subtracting section width ( $A$ in Figure 8$)$ from 234 cumulative bed length of folded and faulted horizon h4 ( $B$ in Figure 8 ) between the pin 235 lines. Note that shortening calculated by this informs total shortening accommodated 236 by faulting and folding, and excludes a component of layer-parallel shortening (such 237 as lateral compaction). The calculated shortening could contain uncertainty arising 238 from vertical compaction and choice of depth conversion. We estimate errors in the 239 shortening are $+/-8 \%$ at maximum, based on multiple parameter tests for the 240 decompaction and depth conversion. This uncertainty is acceptable for our primary 241 purpose that is analysis of along-strike variation rather than of absolute measurement 242 values. 
Finally, we measured the forelimb dip, interlimb angle and depth of anticline crests

244 at horizon h4 (Figure 8). The forelimb dip and interlimb angle were determined on dip sections spaced at every $1 \mathrm{~km}$, the fold crest depth was measured at every $250 \mathrm{~m}$ along fold lengths. We use these measurements to quantify variations in fold tightness

247 and amplitude along strike. Again, up to $15 \%$ errors caused by depth conversion could 248 be included in the measurements of forelimb dip and interlimb angle, and $3 \%$ errors are estimated in the crestal line depth. But overall tendencies of along-strike variations in these measurements should not be affected critically by this uncertainty, as an impact of the depth conversion choice is rather uniform over the study area.

\section{Results}

255

\subsection{Observation of along-strike variations}

\subsubsection{Structural pattern in map view}

On horizon h4, the fold train A extends c. $35 \mathrm{~km}$ along strike within the seismic area and runs northeast beyond the seismic data coverage (Figure 7Figure 6b). The 262 fold train B is c. $48 \mathrm{~km}$ long, has a crest line forming a gentle arc bowed towards the 263 northwest on the map view (Figure 7b). They are widely spaced, at 7-8 km, in the northern section, whereas the fold trains become closer, $3-5 \mathrm{~km}$ distance, in the central section.

Within the mapped segment, the fold train A shows a main culmination plunging southward. This fold train is associated with five fore-thrusts dipping E to SE (FA1, 
268 FA4, FA5, FA6 and FA8) and three oppositely dipping back-thrusts (FA2b, FA3b and 269 FA7b). Some pop-up structures (Butler, 1982) carried by these conjugate thrusts lie 270 along the fold length (e.g. between thrusts FA1 and FA2b). The longest fore-thrust 271 FA4 exhibits a sigmoidal fault trace in the map view whereas the other thrusts display 272 straight or gently bowed traces (Figure 7b). This 'master thrust' (FA4) overlaps the 273 other fore-thrusts (FA5, FA6) in the northern section where it lies within an array of 274 imbricate thrusts (Shaw et al., 1999) (Figure 7b). Thrust FA1 is the only fore-thrust 275 structure that is geometrically isolated from the aligned fore-thrust array on horizon h4. 276 The thrust FA1 forms a relay pattern with the thrust FA4, exhibiting so-called soft 277 linkage (in the sense of Walsh and Watterson, 1991). Above the relay structure there 278 is a deflection in the fold crest line (Figure 7b).

279 The fold train B has two elevation culminations in the central and the northern 280 sections and plunges away to both northeast and south (Figure 7b). The structure 281 contains four fore-thrusts (FB1, FB2, FB3 and FB7) and three back-thrusts (FB4b, 282 FB5b and FB6b). A pop-up structure occurs between conjugate thrusts FB3, FB4b 283 and FB7. The fore-thrust FB1, the largest fault in the study area, has a semi-sigmoidal 284 curvature in map view (Figure $7 \mathrm{~b}$ ), like the master thrust FA4 in the fold train A. The 285 thrust FB1 overlaps all the fore-thrusts along the fold train B to form part of an imbricate thrust array (Figure 7b). Thrusts FB1 and FB7 form a weakly overlapping relay pattern 287 near the northern end of the fold train (Figure 7b). Unlike the fold train A displaying 288 kinks in the fold crest line, the fold train B exhibits a smoother anticline crest line. 289 290 
The seismic sections across the fold trains illustrate the change in fold and thrust 294 geometry along strike (Figure 10). The fold train A shows a low-amplitude kink fold 295 associated with a single fore-thrust FA1 near the southern end (Figure 10b). To the 296 north, the fold changes to tight geometry, more fore- and back-thrusts cut the syn- and 297 pre-kinematic sequences below horizon h5 (Figure 10c). The thrust FA1 terminates 298 and is replaced by the master thrust FA4, the fold becomes asymmetric and verges 299 westward (Figure 10d). The fore-thrust FA1 and back-thrust FA2b and FA3b are not 300 clearly inked to the master thrust FA4 on the seismic image (Figure 10d). The north 301 side of the soft linkage zone between thrusts FA1 and FA4, where the master thrust

302 FA4 forms the embayment trace direction to west, thrust FA4 shows significant 303 displacement associated with a gentle overlying fold geometry (Figure $7 \mathrm{~b}$ and Figure 304 10e). Further to the north, the fold is tightened and more imbricate sheets are 305 developed around the structural culmination along with the back-thrust FA7b (Figure 306 $7 \mathrm{~b}$ and Figure 10f-h). Structurally upper imbricate sheets appear to be younger than 307 underlying sheets, creating a similar structure to 'break-backward imbricate structure' 308 (Shaw et al., 1999), as upper sheets deform stratigraphically younger horizons in the 309 syn-kinematic sequences (e.g. Figure 10g). Back-thrusts show minor displacements compared to fore-thrusts across the fold train A.

311 The fold train B evolves from near its southern end from an asymmetric, low312 amplitude fold verging westward on a single fore-thrust fault FB1 with significant fault 313 displacement (Figure 10a). To the north, more thrusts cut section below horizon h5 314 while the fold shape becomes tight (Figure 10b-e). The thrust FB2 appears to form an 315 isolated segment away from the master thrust FB1 at its southern end (Figure 10b). 316 These structural patterns mimic those of the fold train A described above, and the 317 geometrical changes along strike are accompanied by a decrease in fault 
318 displacement and fault spacing. Analogous to the thrust sequence in the fold train A, 319 upper imbricate thrusts seem to be younger than those below, based on fold 320 deformation in syn-kinematic strata (e.g. Figure 10b, e). In the central section, where 321 one of the fold culminations is located, the fold train B exhibits a symmetric fold shape 322 (Figure 10f). On the north side of this culmination, the fault trace of thrust FB1 bows 323 out to the northwest, the thrust FB1 increases its displacement and accompanies 324 back-thrust FB4b. In accordance with these changes in fault geometry and 325 displacement, the fold evolves to a gentle shape verging east-southeast (Figure 10g). 326 In the northernmost section, where another culmination of the fold train occurs, thrust

327 FB1 reduces offset while accompanying closely spaced thrust faults above (Figure 328 10h). The anticline here shows a tight geometry. Fault displacements accommodated 329 by back-thrusts are minor in comparison with those of fore-thrusts as described for the 330 fold train $\mathrm{A}$.

\subsection{Heave profiles}

Individual thrust faults associated with the fold trains A and B show irregular shapes of heave profiles on a strike projection (Figure 11b, 12b), analogous to displacement337 distance graph for normal faults. Each heave-distance profile, varying from quasi338 elliptical to triangular to bimodal in shape, exhibits single or two heave maxima and diminishes to seismically undetectable heaves at the fault trace ends. Note that complete heave profiles of some thrusts (FA5, FA6, FA7b, FA8, FB6b and FB7) are

341 uncertain, as they extend beyond the seismic area. Thrust FB2 shows large fault 342 heave at the northern end of the trace (Figure 12b). This is because the thrust gets 
close to the upper imbricate thrust FB3, and fault heave on the thrust FB2 becomes

344 seismically unresolvable. Due to this 'fault merger' interpreted below the seismic

345 resolution, the thrust FB3 shows sharply increased fault heave (Figure 12b).

346 The most characteristic patterns of the heave profiles are bimodal shapes 347 associated with the master fore-thrusts, FA4 and FB1 (Figure 11b, 12b). Such uniquely

348 shaped heave profiles do not result from changes in fault dip (Figure 11c, 12c);

349 although the thrust FB1 slightly increases fault dips $\left(29-35^{\circ}\right)$ at its central section

350 where fault heave is diminished, the heave pattern keeps its bimodal shape even if the

351 fault dip effect (heave reduction at c. $20 \%$ ) is removed. These bimodal heave patterns

352 can be explained by the merger of at least two fault segments initiated separately and 353 propagated laterally to coalesce (Ellis and Dunlap, 1988; Liu and Dixon, 1991). Heave 354 maxima of the master thrusts, e.g. at $23 \mathrm{~km}$ and $35 \mathrm{~km}$ along strike for FA4 (Figure 355 11b), indicate places where thrust segments were initiated. These locations 356 correspond to the points in which gentle folds occur and fault traces form westward 357 bow-shapes (Figure 11a, 12a), probably because the faulting played more important 358 role as to the accommodation of shortening than folding there. Local heave minima in 359 the centers of these fault traces, at $28-30 \mathrm{~km}$ for FA4 and $22-27 \mathrm{~km}$ for FB1 along 360 strike (Figure 11b, 12b), are thought to be the sites of former fault linkage (Ellis and 361 Dunlap, 1988). These previous linkage sites coincide with heave peak(s) of imbricate 362 thrust(s) overlying the master thrusts, such as FA5, FB3 and perhaps FB2 (Figure 11b, 363 12b). Given that imbricate thrusts are relatively younger than master thrusts as we 364 described above, these imbricate thrusts appear to be initiated selectively in the fault 365 linkage sites to compensate for the heave deficits on the master thrusts. Nevertheless, 366 these former linkage sites are still marked by decreases in summed heave for each 367 fold train (Figure 11b, 12b). 
Soft linkage sites between thrusts, at $19 \mathrm{~km}$ in fold train $\mathrm{A}$ and at $40 \mathrm{~km}$ in fold train

369 B along strike, are characterized by weakly overlapped heave profiles (Figure 11b, 370 12b). They present distinctive deficits in summed heave for individual fold trains. Near 371 these soft linkage sites, the master thrusts FA4 and FB1 show high heave gradients 372 of $0.18-0.52$ (equivalent to displacement gradients of $0.22-0.56$ ). This contrasts with 373 much of other fore-thrusts and back-thrusts presenting lower heave gradients of 0.043740.16 (displacement gradients of $0.05-0.17$ ) at fault trace ends. These characters are 375 comparable with displacement patterns of normal fault arrays forming soft linkages 376 (e.g. Peacock and Sanderson, 1991). The high heave gradients of the master thrusts 377 suggest that restricted fault-tip propagation (Nicol et al., 1996) of the master thrusts 378 under the interaction with adjacent fault segments (WIllemse et al., 1996; Gupta and 379 Scholz, 2000; Nicol et al., 2016).

380 As if to reflect such restricted fault growth, heave patterns change abruptly across 381 the soft linkage areas. For example, in the south of the soft linkage site in the fold train $382 \mathrm{~A}$, the thrust FA1 and back-thrusts FA2b and FA3b show small heaves and semi383 elliptically shaped heave patterns (Figure 11b). Contrary to this, in the north, thrust 384 faults present increased heaves and irregularly shaped profiles (FA4-FA8) (Figure 385 11b). Given that irregularities in heave profile and high-heave values are produced by 386 segment linkage (Cartwright et al., 1995), the northern regime is thought to be in a 387 more advanced stage of fault growth than the southern area. Small heaves in the south 388 are partly attributed to the thrust FA1 dipping steeply at angles of $40-58^{\circ}$ (Figure 11c). 389 However, even after the consideration of the impact of such large fault dips (heave 390 reduction by $50 \%$ at most), thrusts $\mathrm{FA} 1, \mathrm{FA} 2 \mathrm{~b}$ and FA3b are no match for the thrusts 391 having significant heaves in the north. 
As fault heave on the master thrust FA4 decreases to near zero at its northern end, structurally lowest fore-thrust FA6 increases fault heave, at $28-42 \mathrm{~km}$ along strike 394 (Figure 11b). This is similar to displacement patterns of displacement transfer between relaying thrusts described in outcrops (Dahlstrom, 1969; Sanderson and Spratt, 1992; 396 Davis et al., 2005; Mazzoli et al., 2005).

397

\subsection{Fold strain}

399

As we described above, anticlines carried by thrusts change from gentle to tight 401 folds along their fold lengths. Fluctuations of forelimb dip and interlimb angle of these 402 hangingwall anticlines represent such fold geometry changes along strike 403 systematically (Figure 11d, 12d). The forelimb dip presents particularly rich variation, 404 presumably due to fore-thrust faults that are predominant in the study area.

Along-strike variations of forelimb dip and interlimb angle are here used as fold 406 tightness indexes or proxies for fold strain. They appear to complement summed 407 heave profiles of individual fold trains in part (Figure 11b, 12b). Significant fold strain 408 (tightened fold) represented by decreased interlimb angles $\left(53-70^{\circ}\right)$ and increased 409 forelimb dips $\left(57-64^{\circ}\right)$ occurs at soft linkage sites where summed heave is diminished 410 (Figure 11d, 12d). In the similar way, increased fold strain indicated by large forelimb 411 dips $\left(>45^{\circ}\right)$ along with moderately reduced interlimb angles $\left(70-115^{\circ}\right)$ is distributed on 412 central hard linkages of the master thrusts, where summed heave decreases to form 413 local minima. Some ends of fault traces also present relatively tight fold shapes shown 414 by decreased interlimb angles and increased fault dips, e.g. the southern end of thrust 415 FB1 at 4-8 km and northern end of thrust FB3 at $34 \mathrm{~km}$ along strike (Figure 12b). They 416 might resemble a thrust dying out into a fold, which have been described in natural 
417 structures since the early twentieth century (Elliott, 1976). When summation of heave 418 displays local maxima (e.g. at $23 \mathrm{~km}$ and $12 \mathrm{~km}$ along strike in the fold trains $A$ and $B$, 419 respectively), low fold strain (gentle fold geometry) occurs in thrust hangingwalls with 420 large interlimb angles (106-135 $)$ and gentle forelimb dips (18-31 $\left.{ }^{\circ}\right)$ (Figure 11d, 12d). 421 This shows that fault initiation points accumulate fault slip rather than fold strain.

422 The mirror-image relations between the summed heave and the fold strain indicate 423 displacement transfer between folding and faulting (Elliott, 1976; Liu and Dixon, 1991; 424 Higgins et al., 2009). There are exceptions, however. Local maxima in summation of 425 heave are paired with high fold strain presented by high interlimb angles at c. 30-40 $426 \mathrm{~km}$ along strike in both fold trains (Figure 11b, d, 12b, d). In the area, seismic sections 427 display highly strained structures that are associated with increased number of thrusts 428 and tightened folds (Figure $10 \mathrm{~g}, \mathrm{~h}$ ). Such significant strain may exceed an upper limit where the folding can complement the faulting. Both faulting and folding may have to accommodate shortening as much as they can.

431 The soft linkage site in the fold train A marks the greatest fold strain presented by 432 interlimb angles of $53-63^{\circ}$ and forelimb dip of $57-60^{\circ}$ in the study area (Figure $11 d$ ). 433 Given that summed heave decreases to near zero at the place, these measurements 434 may be nearly equal to a maximum strain attained by the folding mechanism at the horizon h4 without faulting, as far as we can ascertain.

436 The elevations of fold crests show rather smooth profiles along strike (Figure 11e, 437 12e). They display similarities to variations in the forelimb dip and interlimb angle. 438 Increased fold strain indicated by the elevation peaks occurs when the summed heave 439 decreases, e.g. at soft linkage site between FB1 and FB7 and central section of master 440 thrust FB1. Low fold strain is expressed by saddles at places where the summation of 441 heave presents peaks, e.g. c. $24 \mathrm{~km}$ on the fold train $A$ and $13 \mathrm{~km}$ and $35 \mathrm{~km}$ on the 
442 fold train B along strike. But again, northern regime of the study area, at $30-40 \mathrm{~km}$

443 along strike, provides an exception; a crestal culmination occurs with greater summed

444 heave in the fold train A (Figure 11e). This could result from significant strain that 445 needs to be accommodated by both folding and faulting. Note that the crest of the fold 446 train B has been eroded locally, inhibiting complete analysis of its crestal elevation.

\subsection{Shortening in individual fold trains}

450

Shortening is accommodated by three mechanisms theoretically: folding, faulting and layer-parallel shortening (Liu and Dixon, 1991). The shortening calculated in this study, by line-length balancing, only consists of the components associated with the folding and the faulting. Thus, if there is displacement transfer between these two mechanisms along strike as we inferred above, the shortening may reflect a result of such kinematic interaction.

457 In the fold train A, the shortening shows approximately linear increase to north 458 (Figure 11b). This smooth trend of the shortening profile is obvious compared to 459 fluctuated variations in summed heave, forelimb dip and interlimb angle along strike, especially in southern section. This indeed appears to be the product of displacement 461 transfer between folding and faulting (Liu and Dixon, 1991; Higgins et al., 2009). Soft 462 linkage site between thrusts FA1 and FA4 provides a good example. A peak of fold 463 strain illustrated by the smallest interlimb angle and the greatest forelimb dip (Figure 464 11d) compensates cumulative heave decreased to near zero so that shortening presents smooth trend without abrupt gap (Figure 11b). In northern section, there are some deficits in shortening (at 27-31 and 36-38 km along strike) (Figure 11b). In this 
area, increased fold strain indicated by reduced interlimb angle and increased forelimb

468 dip occur, implying that the folding work at full stretch to accommodate shortening.

469 The area is also characterized by large shortening values ( $>2 \mathrm{~km}$ ). Such significant 470 shortening may be over capacity for the fold train A to take the shortening up smoothly 471 along strike only using the folding and the faulting mechanisms.

472 The fold train B shows an irregular shape of shortening profile. Compared to highly

473 fluctuated profile of summed heave along strike, variation in the shortening is slightly 474 moderated (e.g. soft linkage at $40 \mathrm{~km}$ along strike), presumably due to fold strain 475 compensating along-strike change in fault displacement. But, the irregular shape of 476 the shortening profile indicates that such complementary relation between the folding 477 and the faulting did not fully work within the fold train B to accommodate shortening 478 along strike smoothly. Again, a reason for this could be significant shortening 479 excessed a capacity limit of the complementary system between the folding and 480 faulting. Or there may be another mechanism accommodating the shortening.

Difference between the shortening value and summation of heave informs a rough 482 estimate of shortening taken up by the folding. Figure 13 shows that the shortening 483 related to the folding varies along strike in concordance with variations in forelimb dip and interlimb angle (see Figure 11d, 12d for comparison). This fold-related shortening takes up 8-87\% of the shortening amount throughout both fold trains (Figure 13). The 486 ratio of the fold-related shortening to the shortening amount is high at the soft linkage 487 areas $(52-87 \%)$, it becomes moderate at the central hard linkages of master thrusts $488(20-42 \%)$ and lower at the fault initiation points of master thrust segments (8-22 \%). 489 The value of fold-related shortening reaches peaks of c. $1.2 \mathrm{~km}$ at soft linkage sites 490 and at places where imbricate thrust sheets occur (Figure 13), and does not exceed 491 this level. Compared to summation of fault heave reaching $3.7 \mathrm{~km}$ (at $29 \mathrm{~km}$ along 
492 strike in the fold train B), the maximum value of fold-related shortening seems 493 relatively small. The places presented by maxima in the fold-related shortening are 494 characterized by ultimately tightened folds on seismic sections (e.g. Figure $10 \mathrm{~g}, \mathrm{~h}$ ).

495 The value of $1.2 \mathrm{~km}$ may therefore equal to an upper limit of shortening amount that 496 folding can accommodate at horizon h4 in the study area. Note that the shortening 497 amount taken up by the folding also depends on a structural depth of a layer; 498 structurally upper layers can accommodate more shortening value geometrically.

499

500

501 6.5. Total heave and shortening across fold array

502

503

We have seen that individual fold trains present geometric and kinematic variations

504 along strike due to displacement transfer between folds and thrust faults. But, 505 displacement could be transferred from a fold-thrust train to another over few to tens 506 kilometers (Dahlstrom, 1969; Sanderson and Spratt, 1992; Watkins et al., 2017). We 507 now consider fault heave and shortening across both fold trains A and B to see if they 508 demonstrate kinematic coherence.

509 Figure 14a shows that total heave across both fold trains is near zero at the 510 southern end and increases to the peak of $6.7 \mathrm{~km}$ at c. $35 \mathrm{~km}$ along strike while 511 fluctuating, and then declines to the northeast. Although the total heave profile shows 512 some distinctive local peaks (at c. 19, $27 \mathrm{~km}$ along strike) and diminishes (at 10, 25 $513 \mathrm{~km}$ along strike), the profile appears to become closer to a triangular shape generally. 514 It is obvious compared to irregular shapes of summed heave profiles for individual fold 515 trains (Figure 14a). The near linear gradient in total heave appear to be a result of the 516 complementary relation in summed heave between the fold trains. Diminished fault 
517 heaves of individual fold trains are paired with large heaves in another, or vice versa

518 (e.g. 20-27 km along strike; Figure 14a). Kinematically linked fault arrays that

519 propagate laterally produce linear displacement gradients (Cowie and Shipton, 1998;

520 Davis et al., 2005). The fold trains A and B may demonstrate such propagating system

521 by working together.

522 Total shortening across the fold trains presents much linear gradient (Figure 14b).

523 It increases from zero at southern end to the peak of $7.4 \mathrm{~km}$ at $35 \mathrm{~km}$ along strike and

524 then decreases toward the northeast. Smoother gradient in the total shortening is

525 presumably attributed to the folding that accommodates shortening to complement the

526 fluctuation in total heave. The fold train B displays irregular plateau shape in 527 shortening profile at c. $10-40 \mathrm{~km}$ along strike (Figure 14b). This area corresponds to 528 the section where the fold train A accommodates shortening. This may suggest that 529 the fold train A took over the neighboring fold train B to accommodate shortening.

530

531

532

7. Discussion

533

534 7.1. A model for the kinematic linkage of thrusts

535

536 The deep-water fold-thrust belt in offshore NW Borneo described above exhibits a 537 range of structural styles that vary along strike. Along their axes, anticlines vary from 538 gentle open structures to tight folds. These major anticlines lie in the hangingwalls to 539 thrusts. These in turn can vary along strike from single major splays to arrays of 540 smaller imbricate thrusts and local back-thrusts. Fault heave profiles, displaying 541 variations in displacement that we infer, reflect the growth and amalgamation of thrust 
542 segments. Fold strains indicated by forelimb dip and interlimb angle react on the 543 displacement patterns to buffer variation in shortening. Thus, neighboring and

544 adjacent folds appear to be kinematically linked. We now build a model of the evolution 545 of a simplified imbricate thrust system (Figure 15).

546 We have shown that two anticlinal fold trains, A and B, in the 3D seismic survey 547 are defined by the large master thrusts, FA4 and FB1, respectively. These master 548 thrusts are commonly characterized by sigmoidal fault traces in the map view and 549 bimodal heave profiles on the strike projection. Sigmoidal thrust traces are observable 550 in analogue experiments as a result of merger of curved thrust segments (e.g. 551 Schreurs et al., 2016). Displacement pattern along fault traces in outcrops (e.g. Ellis 552 and Dunlap, 1988; Peacock and Sanderson, 1991) and in an analogue experiment 553 (Liu and Dixon, 1991) also suggest that coalescence of fault segments produces 554 diminished displacement at linkage zones. These studies suggest that our master 555 thrusts are the products of merger of at least two thrust segments, which initiated 556 individually, growing together as they accumulated slip (Figure 15a). The two heave 557 maxima correspond to the points of the nucleation of the individual segments. The 558 central heave minima are the location of final linkage between the former discrete 559 segments (Figure 15b). The occurrence of tight fold geometries at the points of heave 560 minima may have their origin in strain localized in the soft linkages (Walsh and 561 Watterson, 1991), or the transfer zones (in sense of O'Keefe and Stearns, 1982; Davis 562 et al., 2005) (Figure 15b). These tight folds complement the heave deficits on the 563 master thrusts, to their limit of shortening amount that the folding mechanism can 564 accommodate. Small, younger imbricate thrusts are selectively initiated in the strained 565 linkage zones to compensate the heave deficits of the master thrusts and to 566 accommodate further shortening that the folding cannot accommodate any more 
567 (Figure 15c). The final thrust geometry created in this way is smoother in three 568 dimensions than the more sculpted forms that would result from a single linkage as 569 the relay ramp was breached (Figure 15d). Lateral propagation of newer, straighter 570 imbricate thrusts above the master thrust appears to create a geometry well-suited to 571 accommodate further shortening. The propagation of such additional structures can 572 be relatively rapid, as suggested by low heave gradients of the imbricate thrusts in the 573 study area.

574 The master thrust we described here is not necessarily the earliest thrust fault 575 developed in a structure; the master thrust FA4 appears to accommodate decreased 576 fault displacement on the structurally lower and older thrust FA6. We assume any 577 thrust faults can follow the steps modelled above if conditions are complete (e.g. 578 alignment of faults), irrespective of thrust sequence. Our model may occur at multiple 579 sites along a single fold train.

580 The deflection along the axis of fold train $A$ is associated with the soft linkage area 581 between thrusts FA1 and FA4 (Figure 15d). We assume this site of soft linkage 582 hampered along-strike propagation of thrust array consisting of FA4, FA5 and FA6, as 583 indicated by high heave gradient of the master thrust. The soft linkage area presents 584 decrease in summed heave and a greater fold strain indicated by small interlimb angle and large forelimb dip. Similar relationships between fold strain and fault linkage sites 586 have been previously inferred (Davis et al., 2005; Higgins et al., 2009). Linear gradient 587 of shortening across the site of soft linkage suggests that the folding plays an important 588 role to maintain the kinematic coherence across the soft linkage area instead of 589 faulting. Given that fold strain is almost at the upper limit for accommodating 590 shortening (c. $1.2 \mathrm{~km}$ ), the soft linkage zone may be verging on a breach by faults to 591 evolve to a hard linkage zone. 
Relative importance of the folding in accommodating the shortening amount varies along strike, depending on the activity of thrust fault(s) and the bulk shortening. At a

594 place where fault propagation is impeded, e.g. by the soft linkage site described above, 595 the folding becomes principal mechanism to accommodate the shortening to 596 compensate the decrease in fault displacement. In an area where the faulting takes 597 up the shortening dominantly, such as fault nucleation points, the folding is less 598 important. Under the significant amount of bulk shortening (e.g. $>2 \mathrm{~km}$ in our case), 599 the folding may exert all its capacity to accommodate shortening together with the 600 faulting. Eventually, the proportion of the shortening taken up by the folding to the bulk 601 shortening can change in a wide range from near 0 to $100 \%$.

602 Our discussions to this point have focused on kinematic linkage of thrust segments 603 associated with a single train of hangingwall anticline. However, our cumulative heave 604 plots and total shortening for the two main fold trains show complementary 605 displacement patterns and shortening profiles. Thus, these two fold-thrust systems 606 appear to work together. Such behavior should be expected. Maximum distance at 607 which fold-thrust structures can work together remains unknown. But, it can be more 608 than $8 \mathrm{~km}$ based on the observable distance between the two fold trains. The regional 609 cross-section (Figure 3b, c) used here to set the scene for our three-dimensional study 610 shows that arrays of fold-thrust structures operated in parallel. They can relay between 611 each other along axis, as predicted by Dahlstrom (1969). Therefore, the occurrence 612 of linkage involving strain localization and imbricate thrusts is dynamically affected by 613 adjacent structures across strike. It is misleading to treat individual fold-thrust 614 structures in isolation.

615 
Kinematic models, such as fault-bend fold (Suppe, 1983; Medwedeff and Suppe, 1997; Suppe et al., 2004), fault-propagation fold (Mitra, 1990; Suppe and Medwedeff, 1990; Mitra and Mount, 1998) and detachment fold (Epard and Groshong, 1995; 622 Poblet and McClay, 1996; Mitra, 2002), illustrate the evolution of the thrust-related 623 folding identified in outcrops and on seismic images while following the balancing 624 theory. They have brought insights into the development process of fold-thrust 625 structures and advances in the prediction of subsurface geometry. Particularly in thrust 626 settings where seismic images are often degraded, advantages to use the kinematic 627 models in testing structural interpretation have been well argued (Hardage et al., 1999;

628 Shaw et al., 2005; Kostenko et al., 2008; Cardozo and Brandenburg, 2014; Malz et al., 629 2015).

630 The kinematic models are simplified and idealized templates of natural structures.

631 They represent large-scale deformation style of the structures, but often fail to account 632 for detailed features of structures (Butler and McCaffrey, 2004; Morley, 2009; Hardy, 633 2011; Torvela and Bond, 2011; Brandes and Tanner, 2013). This is particularly evident 634 in cases where displacement is small. For example, both fault-bend fold and fault635 propagation fold envisage a thrust fault propagated up-dip from a detachment fault. 636 However, at early stage of the fault development, thrust faults can nucleate away from 637 the detachment fault and propagate both up- and down-dip (Williams and Chapman, 638 1983; Kattenhorn, 1994; McConnell et al., 1997; de Vera et al., 2010; Ferrill et al., 639 2016; Ghisetti et al., 2016). In our study area, some of the imbricate thrusts and back640 thrusts marked by small fault heaves appear to show similar characters (e.g. FB2 in 641 Figure 10b, FA1 and FA3b in Figure 10d). Shaw et al. (1999) showed that fault-bend 
642 fold models can describe a variety of imbricate structures. The kinematic models could 643 forecast such structures reasonably only if fault displacement is large enough to

644 develop a linkage between the fore-thrust segment and the detachment fault.

645 Besides, the kinematic models treat cross-sectional geometry basically.

646 Characterization of a fold-thrust structure in three dimensions by them remains 647 challenging, although there are few attempts to expand the algorithms into three 648 dimensions (Cristallini et al., 2004; Cardozo, 2008). The kinematic models may be 649 applied onto serial cross-sections arranged at certain intervals along strike so that 3650 D structural geometry of a structure is apparently illustrated (Wilkerson et al., 1991; 651 Rodriguez-Roa and Wiltschko, 2010). This is in fact desirable approach, because the 652 lateral compatibility of model parameters used is ensured (Watkins et al., 2017). In 653 many cases, however, project time restrictions allow to work only on selected cross654 sections spaced sparsely, 3-D characterization of the structures using kinematic 655 models are roughly attainable.

656 Profiles of geometrical measurements along strike can be made quickly. In this 657 study, we spent less than a day for measuring fault heave, fold limb angles, fold crest 658 depth and shortening. The measurement of fault heave can be especially speedy as 659 it does not require seismic depth conversion. The profiles of these measurements 660 inform very detailed characters of the kinematics underlying the spatial variation in 661 structural style across the structures. Eventually this approach can establish a pseudo 662 three-dimensional view of the kinematic evolution of structures. Although our model, 663 of the relationships between thrust segment linkages and structural complexity, needs 664 to be proven by other studies, if confirmed, they could help forecast structural 665 complexity on low quality seismic dataset. 
Use of kinematic models in combination with analysis of along-strike variation in

667 geometrical measurements may be the best mix. Better understanding obtained

668 through analysis of the geometrical measurement profiles is expected to sharpen an

669 area of interest for analysis with kinematic models, it also provides a guide for model

670 parameters. Thus, a work with the kinematic models could be optimized. The

671 kinematic models in turn can verify the structural geometry of seismic interpretation,

672 and justify the kinematics inferred by the profile analysis. Such conjunction of two

673 methodologies can lead to comprehensive understanding of the 3-D structural

674 geometry and underlying kinematics.

675

676

677 8. Conclusions

678

679 Changes in structural style along two anticlinal trains in a deep-water fold-thrust 680 belt, offshore NW Borneo, were described here using a high-resolution 3D seismic 681 dataset. Use of along-strike profiles of fault heave, shortening and fold geometry 682 measurements are effective for illustrating the kinematic interactions between folds 683 and thrusts, which underlie arrangement of structural variations in the fold-thrust 684 system.

685 Based on our analysis of these profiles allied to structural interpretation, we can 686 conclude the following:

687

688 1. The large master thrusts that define the fold-thrust structures are produced by 689 the amalgamation of two or more thrust faults. The former fault linkages are 690 marked by local heave minima. 
2. The small imbricate thrusts above the master thrust, and increased fold tightness, are spatially associated with sites of former linkage of the master thrust. These additional structures in part compensate for the deficit in heave on the master fault.

3. Folding can accommodate shortening to its limit that mainly depends on structural depth level of a stratigraphic layer. The folding mechanism compensates variation in fault displacement.

4. Adjacent structures in a thrust array can interact both along and across strike. It may be misleading to consider each structure in isolation but rather as a part of a three dimensional, kinematically linked system. It remains unclear over what length-scales these interactions can occur.

702

703

In many thrust systems, subsurface imaging is of a substantially lower quality than

704 for the Borneo data we have used here. Consequently, forecasting subsurface 705 structure has commonly been driven by idealized fold-thrust models (e.g. Shaw et al., 706 2005). This study casts doubt on this approach, as idealized models cannot fully 707 account for structural features marked with small displacement, such as imbricate 708 thrusts and back-thrusts. The fold-thrust models also have a limit to address along709 strike structural variations because they essentially work on the cross-section parallel 710 to the transport direction of rock deformation.

711 Our analysis of geometrical measurements plotted on the strike projection can be 712 readily performed. Particularly heave profile analysis is quickly performed, as fault 713 heave is essentially a measure of horizontal offset and does not require depth 714 conversion. Analysis of along-strike measurement profiles is useful for investigating 715 the kinematic coherence along and across structures. Our study shows that the zones 
716 of greater structural complexity, as marked by greater arrays of imbricate thrusts, 717 coincide with sites of kinematic linkage between the main thrust segments. These in 718 turn coincide with axial deflections of the thrust hangingwall anticlines. These 719 relationships, if confirmed by other studies, could provide useful guides for forecasting 720 structural complexity even when seismic quality is low. Analysis of along-strike 721 variations prior to use of a kinematic model may be beneficial, as along-strike profiles 722 could provide a guide for areas of interest and model parameters.

723

724

\section{Acknowledgements}

726

727 This study is based on part of PhD research funded by INPEX CORPORATION at 728 University of Aberdeen. We acknowledge Petronas for the release of beautiful images 729 of 3D seismic data along with borehole information. We thank Schlumberger for the 730 academic use of Petrel software. We are truly thankful to Nancye Dawers, Haakon 731 Fossen, Roy Gabrielsen and Steve Laubach for their invaluable and constructive 732 comments that considerably improved the manuscript. 


\section{References}

Anders, M.H., Schlische, R.W., 1994. Overlapping Faults, Intrabasin Highs, and the

Algar, S., Milton, C., Upshall, H., Roestenburg, J., Paul Crevello, 2011. MassTransport Deposits of the Deepwater Northwestern Borneo Margin Characterization From Seismic-Reflection, Borehole, and Core Data With Implications for Hydrocarbon Exploration and Exploitation, in: Shipp, R.C., Weimer, P., Posamentier, H.W. (Eds.), Mass-Transport Deposits in Deepwater Settings, SEPM Special Publication 96. Society for Sedimentary Geology, Telsa, Oklahoma, pp. 351-366. Growth of Normal Faults. The Journal of Geology 102, 165-180.

Bellahsen, N., Daniel, J.M., Bollinger, L., Burov, E., 2003. Influence of viscous layers on the growth of normal faults: Insights from experimental and numerical models. Journal of Structural Geology 25, 1471-1485.

Bergen, K.J., Shaw, J.H., 2010. Displacement profiles and displacement-length scaling relationships of thrust faults constrained by seismic-reflection data. Geological Society of America Bulletin 122, 1209-1219.

Brandes, C., Tanner, D.C., 2013. Fault-related folding: A review of kinematic models and their application. Earth-Science Reviews 138, 352-370.

Butler, R.W.H., 1982. The terminology of structures in thrust belts. Journal of Structural Geology 4, 239-245.

Butler, R.W.H., McCaffrey, W.D., 2004. Nature of thrust zones in deep water sandshale sequences: outcrop examples from the Champsaur sandstones of SE France. Marine and Petroleum Geology 21, 911-921.

Cardozo, N., 2008. Trishear in 3D. Algorithms, implementation, and limitations. Journal of Structural Geology 30, 327-340.

Cardozo, N., Brandenburg, J.P., 2014. Kinematic modeling of folding above listric propagating thrusts. Journal of Structural Geology 60, 1-12.

Cartwright, J.A., Trudgill, B.D., Mansfield, C.S., 1995. Fault growth by segment linkage: an explanation for scatter in maximum displacement and trace length data from the Canyonlands Grabens of SE Utah. Journal of Structural Geology $17,1319-1326$.

Childs, C., Watterson, J., Walsh, J.J., 1995. Fault overlap zones within developing normal fault systems. Journal of the Geological Society $152,535-549$.

Cowie, P.A., Scholz, C., 1992. Displacement-length scaling relationship for faults: data synthesis and discussion. Journal of Structural Geology 14, 1149-1156.

Cowie, P.A., Shipton, Z.K., 1998. Fault tip displacement gradients and process zone dimensions. Journal of Structural Geology 20, 983-997. 
Cristallini, E.O., Giambiagi, L., Allmendinger, R.W., 2004. True three-dimensional trishear: A kinematic model for strike-slip and oblique-slip deformation. Bulletin of the Geological Society of America 116, 938-952.

Cullen, A.B., 2010. Transverse segmentation of the Baram-Balabac Basin, NW Borneo: refining the model of Borneo's tectonic evolution. Petroleum Geoscience 16, 3-29.

Dahlstrom, C.D.A., 1969. Balanced cross sections. Canadian Journal of Earth Sciences 6, 743-757.

Davis, K., Burbank, D.W., Fisher, D., Wallace, S., Nobes, D., 2005. Thrust-fault growth and segment linkage in the active Ostler fault zone, New Zealand. Journal of Structural Geology 27, 1528-1546.

Dawers, N.H., Anders, M.H., 1995. Displacement-length scaling and fault linkage. Journal of Structural Geology 17, 607-614.

Dawers, N.H., Anders, M.H., Scholz, C.H., 1993. Growth of normal faults: Displacement-length scaling. Geology 21, 1107-1110.

de Vera, J., Granado, P., McClay, K., 2010. Structural evolution of the Orange Basin gravity-driven system, offshore Namibia. Marine and Petroleum Geology 27, 223237.

Elliott, D., 1976. The Energy Balance and Deformation Mechanisms of Thrust Sheets. Philosophical Transactions of the Royal Society A: Mathematical, Physical and Engineering Sciences 283, 289-312.

Ellis, M.A., Dunlap, W.J., 1988. Displacement variation along thrust faults: implications for the development of large faults. Journal of Structural Geology 10, 183-192.

Epard, J.-L., Groshong, R.H.J., 1995. Kinematic model of detachment folding including limb rotation, fixed hinges and layer-parallel strain. Tectonophysics 247, 85-103.

Fermor, P., 1999. Aspects of the three-dimensional structure of the Alberta Foothills and Front Ranges. Geological Society of America Bulletin 111, 317-346.

Ferrill, D.A., Morris, A.P., Wigginton, S.S., Smart, K.J., McGinnis, R.N., Lehrmann, D., 2016. Deciphering thrust fault nucleation and propagation and the importance of footwall synclines. Journal of Structural Geology 85, 1-11.

Franke, D., Barckhausen, U., Heyde, I., Tingay, M., Ramli, N., 2008. Seismic images of a collision zone offshore NW Sabah/Borneo. Marine and Petroleum Geology $25,606-624$.

Gardner, D.A.C., Spang, J.H., 1973. Model Studies of the Displacement Transfer Associated with Overthrust Faulting. Bulletin of Canadian Petroleum Geology 4, 534-552.

Ghisetti, F.C., Barnes, P.M., Ellis, S., Plaza-Faverola, A.A., Barker, D.H.N., 2016. The last $2 \mathrm{Myr}$ of accretionary wedge construction in the central Hikurangimargin 
(North Island, New Zealand): Insights fromstructuralmodeling. Geochemistry Geophysics Geosystems 17, 2661-2686.

811

812

813

814

815

816

817

818

819

820

821

822

823

824

825

826

827

828

829

830

831

832

833

834

835

836

837

838

839

840

841

842

843

844

Giba, M., Walsh, J.J., Nicol, A., 2012. Segmentation and growth of an obliquely reactivated normal fault. Journal of Structural Geology 39, 253-267.

Groshong, R.H.J., Bond, C.E., Gibbs, A.D., Ratliff, R., Wiltschko, D. V., 2012. Preface: Structural balancing at the start of the 21st century: 100 years since Chamberlin. Journal of Structural Geology 41, 1-5.

Groshong, R.H.J., Epard, J.-L., 1994. The role of strain in area-constant detachment folding. Journal of Structural Geology 16, 613-618.

Gupta, A., Scholz, C.H., 2000. A model of normal fault interaction based on observations and theory. Journal of Structural Geology 22, 865-879.

Hall, R., 2013. Contraction and extension in northern Borneo driven by subduction rollback. Journal of Asian Earth Sciences 76, 399-411.

Hardage, B.A., Pendleton, V.M., Major, R.P., Asquith, G.B., Schultz-eia, D., Lancasterft, D.E., 1999. Case History Using petrophysics and cross-section balancing to interpret complex structure in a limited-quality 3-D seismic image. Geophysics 64, 1760-1773.

Hardy, S., 2011. Cover deformation above steep, basement normal faults: Insights from 2D discrete element modeling. Marine and Petroleum Geology 28, 966-972.

Hazebroek, H.P., Tan, D.N.K., 1993. Tertiary tectonic evolution of the NW Sabah continental margin. Bulletin of the Geological Society of Malaysia 33, 195-210.

Hesse, S., Back, S., Franke, D., 2010. Deepwater folding and thrusting offshore NW Borneo, SE Asia. Geological Society, London, Special Publications 348, 169-185.

Hesse, S., Back, S., Franke, D., 2009. The deep-water fold-and-thrust belt offshore NW Borneo: Gravity-driven versus basement-driven shortening. Geological Society of America Bulletin 121, 939-953.

Higgins, S., Clarke, B., Davies, R.J., Cartwright, J., 2009. Internal geometry and growth history of a thrust-related anticline in a deep water fold belt. Journal of Structural Geology 31, 1597-1611.

Higgins, S., Davies, R.J., Clarke, B., 2007. Antithetic fault linkages in a deep water fold and thrust belt. Journal of Structural Geology 29, 1900-1914.

Hinz, K., Fritsch, J., Kempter, E.H.K., Mohammad, a. M., Meyer, J., Mohamed, D., Vosberg, H., Weber, J., Benavidez, J., 1989. Thrust tectonics along the northwestern continental margin of Sabah/Borneo. Geologische Rundschau 78, 705730.

Hutchison, C.S., 2010. The North-West Borneo Trough. Marine Geology 271, 32-43.

Hutchison, C.S., 2005. Geology of North-West Borneo: Sarawak, Brunei and Sabah, 
First. ed. Elsevier.

847

848

849

850

851

852

853

854

855

856

857

858

859

860

861

862

863

864

865

866

867

868

869

870

871

872

873

874

875

876

877

878

879

880

881

882

883

Ingram, G.M., Chisholm, T.J., Grant, C.J., Hedlund, C.A., Stuart-Smith, P., Teasdale, J., 2004. Deepwater North West Borneo: hydrocarbon accumulation in an active fold and thrust belt. Marine and Petroleum Geology 21, 879-887.

Jackson, C.A.-L., Gawthorpe, R.L., Sharp, I.R., 2002. Growth and linkage of the East Tanka fault zone, Suez rift: structural style and syn-rift stratigraphic response. Journal of the Geological Society 159, 175-187.

Kattenhorn, S.A., 1994. Outcrop-scale fault-related folds, Valley and Ridge Province, Appalachians: comparison to kinematic model predictions. The University of Akron.

Kim, Y.-S., Sanderson, D.J., 2005. The relationship between displacement and length of faults: a review. Earth-Science Reviews 68, 317-334.

King, G., Yielding, G., 1984. The evolution of a thrust fault system: processes of rupture initiation, propagation and termination in the 1980 El Asnam (Algeria) earthquake. Geophysical Journal of the Royal Astronomical Society 77, 915-933.

Kostenko, O. V., Naruk, S.J., Hack, W., Poupon, M., Meyer, H.-J., Mora-Glukstad, M., Anowai, C., Mordi, M., 2008. Structural evaluation of column-height controls at a toe-thrust discovery, deep-water Niger Delta. American Association of Petroleum Geologists Bulletin 92, 1615-1638.

Liu, S., Dixon, J.M., 1991. Centrifuge modelling of thrust faulting: structural variation along strike in fold-thrust belts. Tectonophysics 188, 39-62.

Lu, H., Shipp, R.C., 2011. Impact of a Large Mass-Transport Deposit on a Field Development in the Upper Slope of Southwestern Sabah, Malaysia, Offshore Northwest Borneo, in: Mass-Transport Deposits in Deepwater Settings, SEPM Special Publication 96. pp. 199-218.

Malz, A., Madritsch, H., Kley, J., 2015. Improving 2D seismic interpretation in challenging settings by integration of restoration techniques: A case study from the Jura fold-and-thrust belt. Interpretation 3, SAA37-SAA58.

Mansfield, C., Cartwright, J., 2001. Fault growth by linkage: Observations and implications from analogue models. Journal of Structural Geology 23, 745-763.

Mazzoli, S., Pierantoni, P.P., Borraccini, F., Paltrinieri, W., Deiana, G., 2005. Geometry, segmentation pattern and displacement variations along a major Apennine thrust zone, central Italy. Journal of Structural Geology 27, 1940-1953.

McConnell, D.A., Kattenhorn, S.A., Benner, L.M., 1997. Distribution of fault slip in outcrop-scale fault-related folds, appalachian mountains. Journal of Structural Geology 19, 257-267.

Medwedeff, D.A., Suppe, J., 1997. Multibend fault-bend folding. Journal of Structural Geology 19, 279-292. 
Meyer, V., Nicol, A., Childs, C., Walsh, J.J., Watterson, J., 2002. Progressive localisation of strain during the evolution of a normal fault population. Journal of Structural Geology 24, 1215-1231.

Mitra, S., 2002. Structural models of faulted detachment folds. American Association of Petroleum Geologists Bulletin 86, 1673-1694.

Mitra, S., 1990. Fault-Propagation Folds: Geometry, Kinematic Evolution, and Hydrocarbon Traps (1). American Association of Petroleum Geologists Bulletin 74, 921-945.

Mitra, S., Mount, S. Van, 1998. Foreland basement-involved structures. AAPG Bulletin 82, 70-109.

Morley, C.K., 2009. Geometry of an oblique thrust fault zone in a deepwater fold belt from 3D seismic data. Journal of Structural Geology 31, 1540-1555.

Morley, C.K., 2007. Interaction between critical wedge geometry and sediment supply in a deep-water fold belt. Geology 35, 139.

Morley, C.K., Back, S., 2008. Estimating hinterland exhumation from late orogenic basin volume, NW Borneo. Journal of the Geological Society 165, 353-366.

Morley, C.K., Back, S., Van Rensbergen, P., Crevello, P., Lambiase, J.J., 2003. Characteristics of repeated, detached, Miocene-Pliocene tectonic inversion events, in a large delta province on an active margin, Brunei Darussalam, Borneo. Journal of Structural Geology 25, 1147-1169.

Morley, C.K., King, R., Hillis, R.R., Tingay, M., Backé, G., 2011. Deepwater fold and thrust belt classification, tectonics, structure and hydrocarbon prospectivity: A review. Earth-Science Reviews 104, 41-91.

Morley, C.K., Tingay, M., Hillis, R.R., King, R., 2008. Relationship between structural style, overpressures, and modern stress, Baram Delta Province, northwest Borneo. Journal of Geophysical Research 113, 1-23.

Morley, C.K., Warren, J., Tingay, M., Boonyasaknanon, P., Julapour, A., 2014. Comparison of modern fluid distribution, pressure and flow in sediments associated with anticlines growing in deepwater (Brunei) and continental environments (Iran). Marine and Petroleum Geology 51, 210-229.

Nicol, A., Childs, C., Walsh, J.J., Manzocchi, T., Scho, M.P.J., Hutt, L., Zealand, N., Group, F.A., 2016. Interactions and growth of faults in an outcrop-scale system. The Geological Society of London Special Publication 439.

Nicol, A., Gillespie, P.A., Childs, C., Walsh, J.J., 2002. Relay zones between mesoscopic thrust faults in layered sedimentary sequences. Journal of Structural Geology 24, 709-727.

Nicol, A., Watterson, J., Walsh, J.J., Childs, C., 1996. The shapes, major axis orientations and displacement patterns of fault surfaces. Journal of Structural Geology 18, 235-248. 
O'Keefe, F.X., Stearns, D.W., 1982. Characteristics of displacement transfer zones associated with thrust faults, in: Geologic Studies of the Cordilleran Thrust Belt. pp. 219-233.

Peacock, D.C.P., Sanderson, D.J., 1991. Displacement, segment linakge and relay ramps in normal fault zones. Journal of Structural Geology 13, 721-733.

Petronas, 1999. The Petroleum Geology and Resources of Malaysia. Petroliam Nasional Berhad (PETRONAS), Kuala Lumpur.

Poblet, J., McClay, K., 1996. Geometry and Kinematics of Single-Layer Detachment Folds. American Association of Petroleum Geologists Bulletin 80, 1085-1109.

Rodriguez-Roa, F.A., Wiltschko, D. V., 2010. Thrust belt architecture of the central and southern Western Foothills of Taiwan. Geological Society, London, Special Publications 348, 137-168.

Sanderson, D.A., Spratt, D.A., 1992. Triangle zone and displacement transfer structures in the eastern Front Ranges, southern Canadian Rocky Mountains. American Association of Petroleum Geologists Bulletin 76, 828-839.

Sapin, F., Hermawan, I., Pubellier, M., Vigny, C., Ringenbach, J.-C., 2013. The recent convergence on the NW Borneo Wedge - a crustal-scale gravity gliding evidenced from GPS. Geophysical Journal International 193, 549-556.

Sapin, F., Pubellier, M., Lahfid, A., Janots, D., Aubourg, C., Ringenbach, J.-C., 2011. Onshore record of the subduction of a crustal salient: example of the NW Borneo Wedge. Terra Nova 23, 232-240.

Scherer, F.C., 1980. Exploration in East Malaysia of the past decade. Giant Oil and Gas Fields of the Decade 1968-1978 30, 423-440.

Schlagenhauf, A., Manighetti, I., Malavieille, J., Dominguez, S., 2008. Incremental growth of normal faults: Insights from a laser-equipped analog experiment. Earth and Planetary Science Letters 273, 299-311.

Schlische, R.W., Young, S.S., Ackermann, R. V., Gupta, A., 1996. Geometry and scaling relations of a population of very small rift-related normal faults. Geology 24, 683-686.

Schreurs, G., Buiter, S.J.H., Boutelier, J., Burberry, C., Callot, J.P., Cavozzi, C., Cerca, M., Chen, J.H., Cristallini, E., Cruden, A.R., Cruz, L., Daniel, J.M., Da Poian, G., Garcia, V.H., Gomes, C.J.S., Grall, C., Guillot, Y., Guzm??n, C., Hidayah, T.N., Hilley, G., Klinkm??ller, M., Koyi, H.A., Lu, C.Y., Maillot, B., Meriaux, C., Nilfouroushan, F., Pan, C.C., Pillot, D., Portillo, R., Rosenau, M., Schellart, W.P., Schlische, R.W., Take, A., Vendeville, B., Vergnaud, M., Vettori, M., Wang, S.H., Withjack, M.O., Yagupsky, D., Yamada, Y., 2016. Benchmarking analogue models of brittle thrust wedges. Journal of Structural Geology 92, 116-139.

Shaw, J.H., Bilotti, F., Brennan, P.A., 1999. Patterns of imbricate thrusting. Bulletin of the Geological Society of America 111, 1140-1154. 
962

963

964

965

966

967

968

969

970

971

972

973

974

975

976

977

978

979

980

981

982

983

984

985

986

987

988

989

990

991

992

993

994

995

996

997

998

999

Shaw, J.H., Connors, C.D., Suppe, J., 2005. Structural interpretation methods, in: Seismic Interpretation of Contractional Fault-Related Folds, An AAPG Seismic Atlas. pp. 2-58.

Simons, W.J.F., Socquet, A., Vigny, C., Ambrosius, B.A.C., Abu, S.H., Promthong, C., Subarya, C., Sarsito, D.A., Matheussen, S., Morgan, P., Spakman, W., 2007. A decade of GPS in Southeast Asia: Resolving Sundaland motion and boundaries. Journal of Geophysical Research: Solid Earth 112, 1-20.

Soliva, R., Benedicto, A., 2004. A linkage criterion for segmented normal faults. Journal of Structural Geology 26, 2251-2267.

Suppe, J., 1983. Geometry and kinematics of fault-bend folding. American Journal of Science 283, 684-721.

Suppe, J., Connors, C.D., Zhang, Y., 2004. Shear Fault-bend Folding, in: McClay, K.R. (Ed.), Thrust Tectonics and Hydrocarbon Systems: AAPG Memoir 82. American Association of Petroleum Geologists, pp. 303-323.

Suppe, J., Medwedeff, D.A., 1990. Geometry and kinematics of fault-propagation folding. Eclogae Geologicae Helvetiae 454, 409-454.

Tan, D.N.K., Lamy, J.M., 1990. Tectonic evolution of the NW Sabah continental margin since the Late Eocene. Geological Society of Malaysia, Bulletin 27, 241-260.

Torvela, T., Bond, C.E., 2011. Do experts use idealised structural models? Insights from a deepwater fold-thrust belt. Journal of Structural Geology 33, 51-58.

Walsh, J.J., Bailey, W.R., Childs, C., Nicol, A., Bonson, C.G., 2003. Formation of segmented normal faults: A 3-D perspective. Journal of Structural Geology 25, 1251-1262.

Walsh, J.J., Watterson, J., 1991. Geometric and kinematic coherence and scale effects in normal fault systems. Geological Society, London, Special Publications 56, 193-203.

Watkins, H., Butler, R.W.H., Bond, C.E., 2017. Using laterally compatible cross sections to infer fault growth and linkage models in foreland thrust belts. Journal of Structural Geology 96, 102-117.

Wilkerson, S.M., Medwedeff, D.A., Marshak, S., 1991. Geometrical modeling of faultrelated folds: a pseudo-three-dimensional approach. Journal of Structural Geology 13, 801-812.

Williams, G., Chapman, T., 1983. Strains developed in the hangingwalls of thrusts due to their slip/propagation rate: A dislocation model. Journal of Structural Geology 5, 563-571.

WIllemse, E.J.M., Pollard, D.D., Aydin, A., 1996. Three-dimensional analyses of slip distributions on normal fault arrays with consequences for fault scaling. Pergamon Journal of Structural Geology 18, 295-309. 
1000 Wyrick, D.Y., Morris, A.P., Ferrill, D.A., 2011. Normal fault growth in analog models 1001 and on Mars. Icarus 212, 559-567.

1002 
1003

1004

1005

1006

1007

1008

1009

1010

1011

1012

1013

1014

1015

1016

1017 Figure 3. Location map and regional 2D seismic profile of offshore Northwest Borneo.

1018 (a) Regional tectonic map of the offshore area of Northwest Borneo. Inset shows map 1019 location in Southeast Asia. Fault map is modified from Cullen (2010) and is 1020

1021 Dashed line shows bathymetric contours at the interval of $500 \mathrm{~m}$. Filled gray rectangle 1022 is location of 3D seismic data used in this study. (b) Regional 2D seismic profile of 1023 "Line A" and (c) a structural interpretation of the seismic profile. Profiles are displayed 1024 at no vertical exaggeration with an assumption of the average seismic velocity of 2.7 $1025 \mathrm{~km} / \mathrm{s}$. Principal unconformities are labelled on the horizons; SCSU = South China Sea 1026 Unconformity (Early Miocene), M/P = Miocene-Pliocene boundary ( 5.3 Ma), L/UP = 
1027 Lower/Upper Pliocene boundary ( 3.6 Ma) and P/Q = Pliocene/Quaternary boundary $1028(\sim 1.8 \mathrm{Ma})$.

1029

1030 Figure 4. Perspective view of 3D seismic survey with (a) syn-kinematic horizon h7, 1031 and (b) top pre-kinematic horizon h4. Two-way arrows show sail-line orientations of 1032 multi-azimuth survey. Translucent planes with dashed border lines are location of a 1033 dip section shown in Figure 5. Four wells (Well 1 to 4) were tied into seismic survey 1034 with sonic logs and check shot surveys. Only seismic volume within full-fold area is 1035 displayed. Elevation of horizons is displayed in two-way time with contour interval of $1036100 \mathrm{~ms}$. The survey location is in Figure 3.

1037

1038 Figure 5. A dip profile of 3D seismic survey. (a) Uninterpreted and (b) interpreted 1039 seismic profile. Multi-layered reflectors of turbiditic sequences interbed with 1040 seismically chaotic mass transport deposits. Pre-, Syn- and Post-kinematic strata are 1041 identified based on structural patterns. White rectangle shows area of Figure 6 . 1042 Location of the profile is shown in Figure 4. Profiles are displayed at no vertical 1043 exaggeration with an assumption of the average seismic velocity of $2.7 \mathrm{~km} / \mathrm{s}$.

1044

1045 Figure 6. Correlation between gamma-ray log response and seismic character at Well 10463 location. Low gamma-ray, sandy sequences correspond with reflective packages 1047 while high gamma-ray, shaly intervals match with less reflective characters on seismic 1048 image. Formation ages presented alongside the profile are based on biostratigraphic 1049 analysis. See Figure 4, 5 for profile location. The profile has no vertical exaggeration 1050 with an assumption of the average seismic velocity of $2.7 \mathrm{~km} / \mathrm{s}$. 
1052 Figure 7. Elevation maps of key seismic horizons. (a) Syn-kinematic horizon h7. (b)

1053 Top Pre-kinematic horizon h4. Red lines with triangles show trace of fore-thrusts and 1054 orange lines with triangles are of back-thrusts in the hangingwalls. Major thrusts are 1055 labelled. White diagonal crosshatch indicates area of erosions on fold crest. Lines a 1056 to $\mathrm{h}$ are locations of seismic profiles in Figure 10. Contour interval is $100 \mathrm{~m}$.

1057

1058 Figure 8. Diagram of structural geometry measured for quantifying along-strike 1059 variations on fold-thrust structures. $h$ : fault heave, $\alpha$ : forelimb dip, $\beta$ : interlimb angle, 1060 Y: fault dip, A: width of section, B: bed length. A subtracted from B leaves approximate 1061 estimate of the shortening amount.

1062

1063 Figure 9. Relationship between fault heave, dip-separation and fault dip angle. 1064 Measurements only for thrusts with significant displacements are plotted (FA1, FA4, 1065 FA5, FA6, FA7b, FA8, FB1, FB2, FB3, FB4b, FB7). As fault dip increases, difference 1066 between fault heave and dip-separation increases.

1067

1068 Figure 10. Selected seismic sections perpendicular to fold trains. Locations of sections 1069 are shown in Figure 7. Profiles are displayed at approximately no vertical exaggeration 1070 with an assumption of the average seismic velocity of $2.7 \mathrm{~km} / \mathrm{s}$. Major thrust faults are 1071 labelled. High-resolution images are provided in the Supplemental Materials.

1072

1073 Figure 11. Along-strike variations of the fold train A on strike projection. (a) Depth map 1074 of horizon h4 with thrust fault traces. Contour interval is at $100 \mathrm{~m}$. (b) Fault heave and 1075 shortening value, (c) Fault dip angle for selected thrusts, (d) forelimb dip and interlimb 1076 angle, and (e) Depth to fold crest of horizon h4. 
1078 Figure 12. Along-strike variations of the fold train B on strike projection. (a) Depth map 1079 of horizon h4 with thrust fault traces. Contour interval is at $100 \mathrm{~m}$. (b) Fault heave and 1080 shortening value, (c) Fault dip angle for selected thrusts, (d) forelimb dip and interlimb 1081 angle, and (e) Depth to fold crest of horizon h4.

1082

1083 Figure 13. Fold-related shortening along strike for (a) Fold train A and (b) Fold train B. 1084 Difference between shortening (solid gray line) and summed heave (dotted gray line) 1085 provides rough estimate of shortening accommodated by folding (dash-dotted black 1086 line). Maximum values of fold-related shortening, c. $1 \mathrm{~km}$, appears to be an upper limit 1087 where folding can accommodate shortening at horizon h4.

1088

1089

Figure 14. (a) Total fault heave and (a) Total shortening across fold trains A and B. 1090 Summed fault heave and shortening for individual fold trains are displayed for 1091 comparison. Total fault heave and total shortening present generally linear gradients, 1092 implying kinematic coherence between the fold trains.

1093

1094 Figure 15. A model for the evolution of fold-thrust structures. (a) Early stage of fold1095 thrust belt development. At this stage, individual structure segments are geometrically 1096 isolated. Increased strain is distributed between closely neighboring structures. (b) 1097 Hard linkage of aligned segments is established as structures laterally propagate. 1098 Increased fold strain is distributed in linkage site due to decreased fault displacement. 1099 (c) Imbricate thrusts occur on former linkage site to compensate for diminished fault 1100 displacement. Soft linkage site is developed as non-aligned structures approach. (d) 1101 Imbricate thrusts dominantly accommodate shortening on linked segments. 
1102 Accumulated fold strain on soft linkage site between non-aligned structures forms 1103 deflection in fold hinge. See text for further explanation. 


\section{Supplemental Material captions}

1105

1106 Supplemental Material 1a. High-resolution image of seismic section a-a' without

1107 author's interpretation (equivalent to left panel of Figure 10a).

1108

1109 Supplemental Material 1b. High-resolution image of seismic section a-a' with author's 1110 interpretation (equivalent to right panel of Figure 10a).

1111

1112 Supplemental Material 2a. High-resolution image of seismic section b-b' without 1113 author's interpretation (equivalent to left panel of Figure 10b).

1114

1115 Supplemental Material 2b. High-resolution image of seismic section b-b' with author's 1116 interpretation (equivalent to right panel of Figure 10b).

1118 Supplemental Material 3a. High-resolution image of seismic section c-c' without 1119 author's interpretation (equivalent to left panel of Figure 10c).

1120

1121 Supplemental Material 3b. High-resolution image of seismic section c-c' with author's 1122 interpretation (equivalent to right panel of Figure 10c).

1123

1124 Supplemental Material 4a. High-resolution image of seismic section d-d' without 1125 author's interpretation (equivalent to left panel of Figure 10d).

1126

1127 Supplemental Material 4b. High-resolution image of seismic section d-d' with author's 1128 interpretation (equivalent to right panel of Figure 10d). 
1130 Supplemental Material 5a. High-resolution image of seismic section e-e' without 1131 author's interpretation (equivalent to left panel of Figure 10e).

1133 Supplemental Material 5b. High-resolution image of seismic section e-e' with author's 1134 interpretation (equivalent to right panel of Figure 10e).

1135

1136 Supplemental Material 6a. High-resolution image of seismic section f-f' without 1137 author's interpretation (equivalent to left panel of Figure 10f).

1139 Supplemental Material 6b. High-resolution image of seismic section f-f' with author's 1140 interpretation (equivalent to right panel of Figure 10f).

1142 Supplemental Material 7a. High-resolution image of seismic section g-g' without 1143 author's interpretation (equivalent to left panel of Figure 10g).

1145 Supplemental Material 7b. High-resolution image of seismic section g-g' with author's 1146 interpretation (equivalent to right panel of Figure 10g).

1148 Supplemental Material 8a. High-resolution image of seismic section h-h' without 1149 author's interpretation (equivalent to left panel of Figure 10h).

1150

1151 Supplemental Material 8b. High-resolution image of seismic section h-h' with author's 1152 interpretation (equivalent to right panel of Figure 10h). 
Figure 1
Click here to download high resolution image

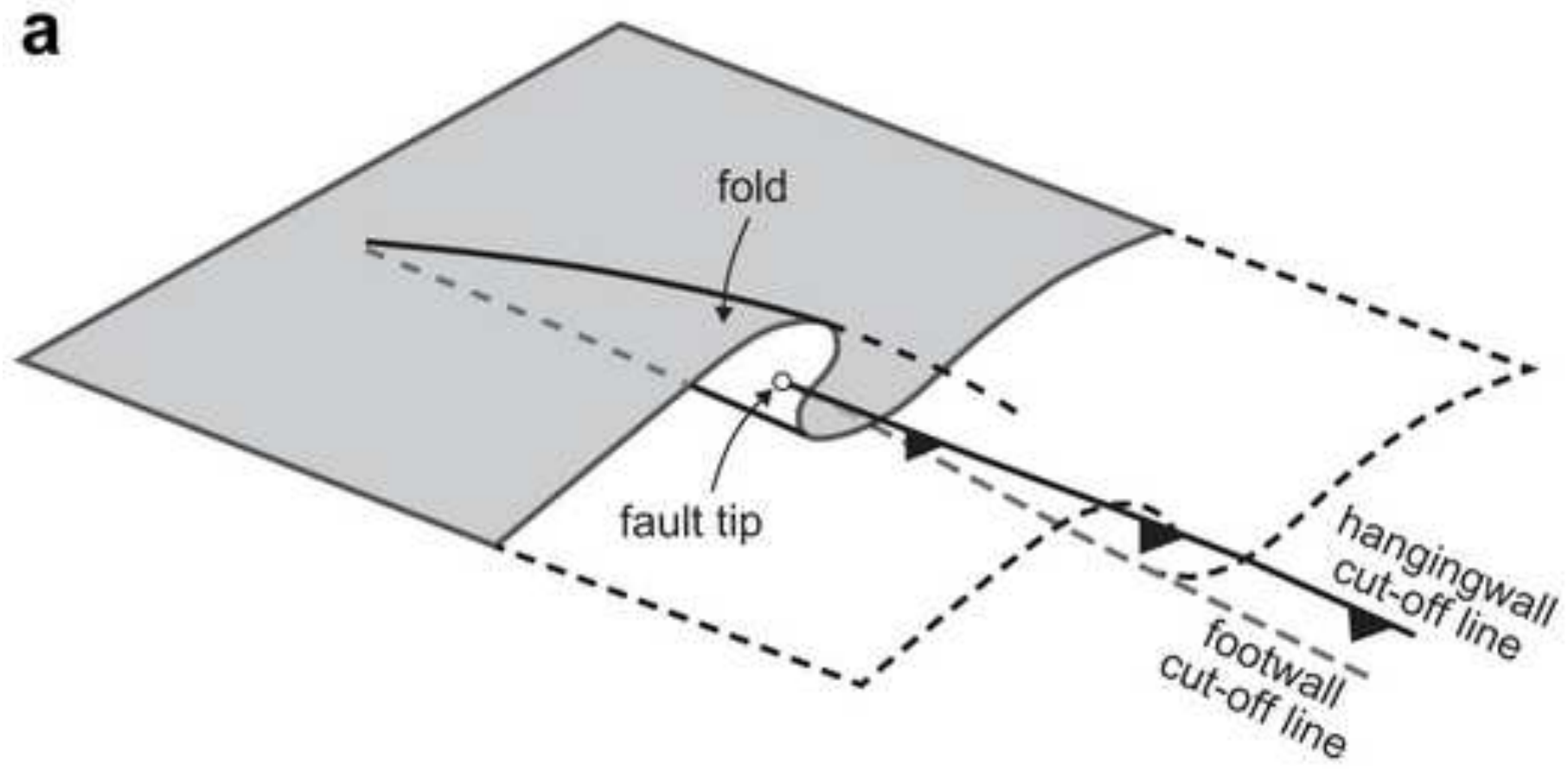

b

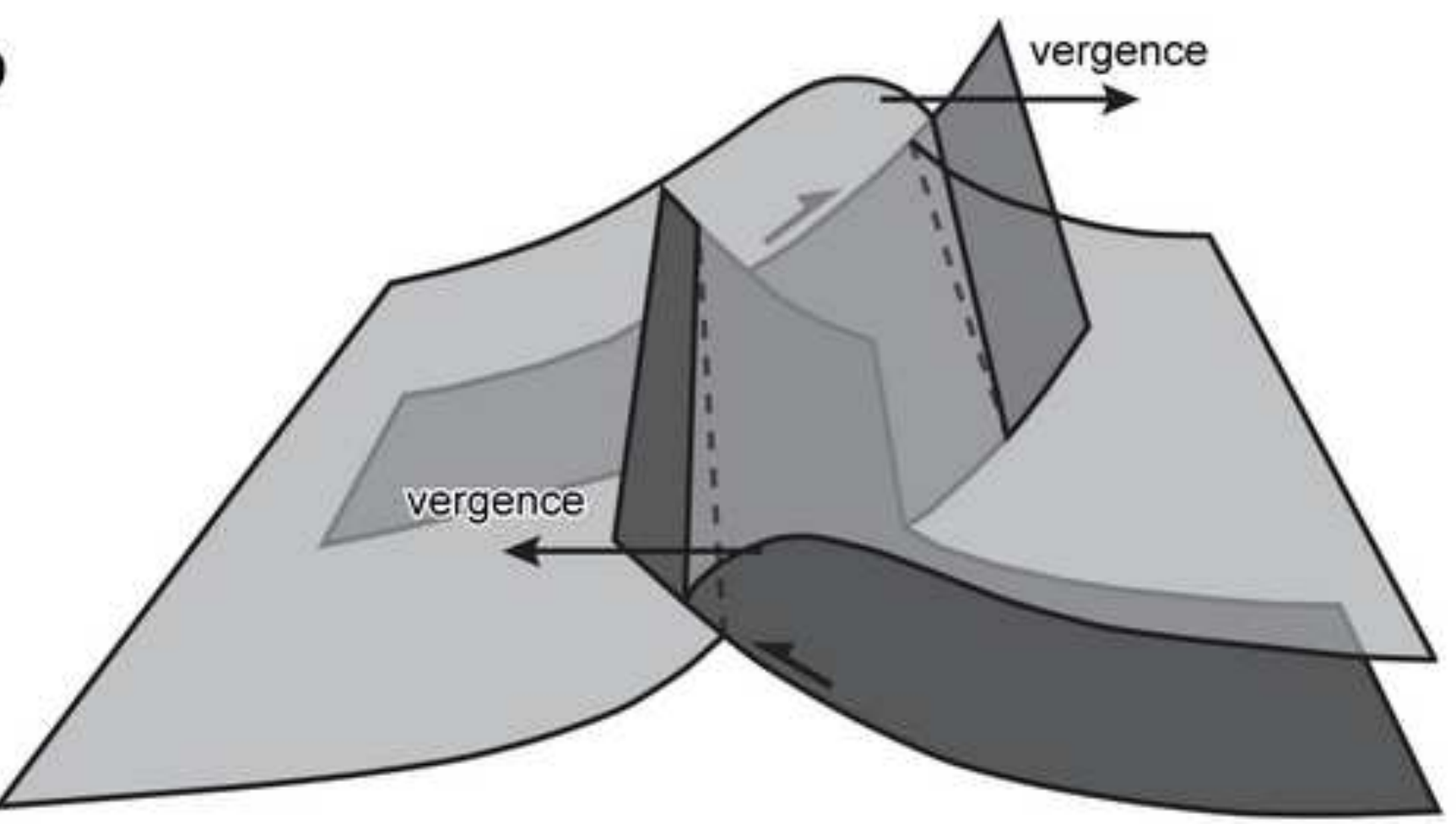


Click here to download high resolution image

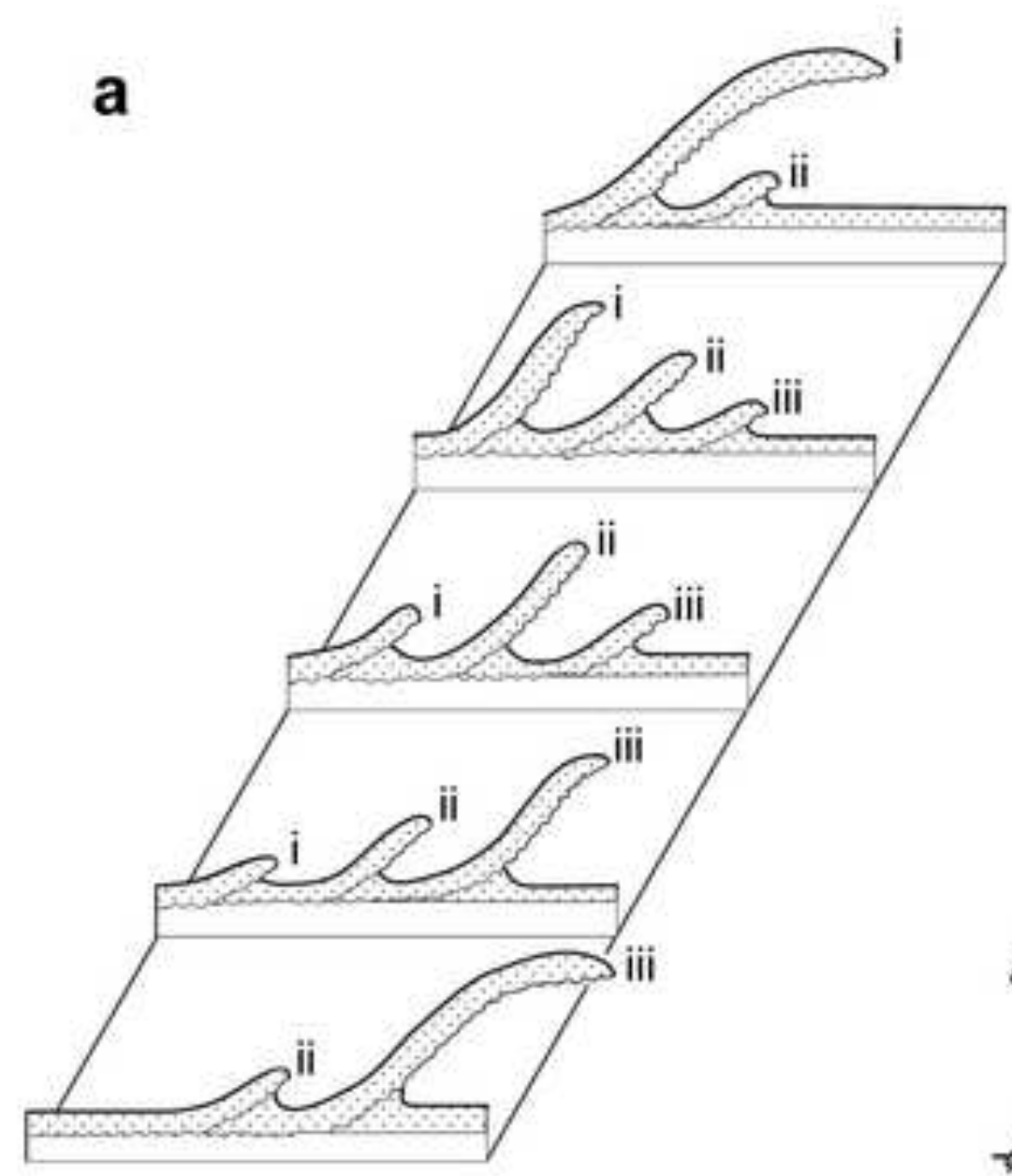

b

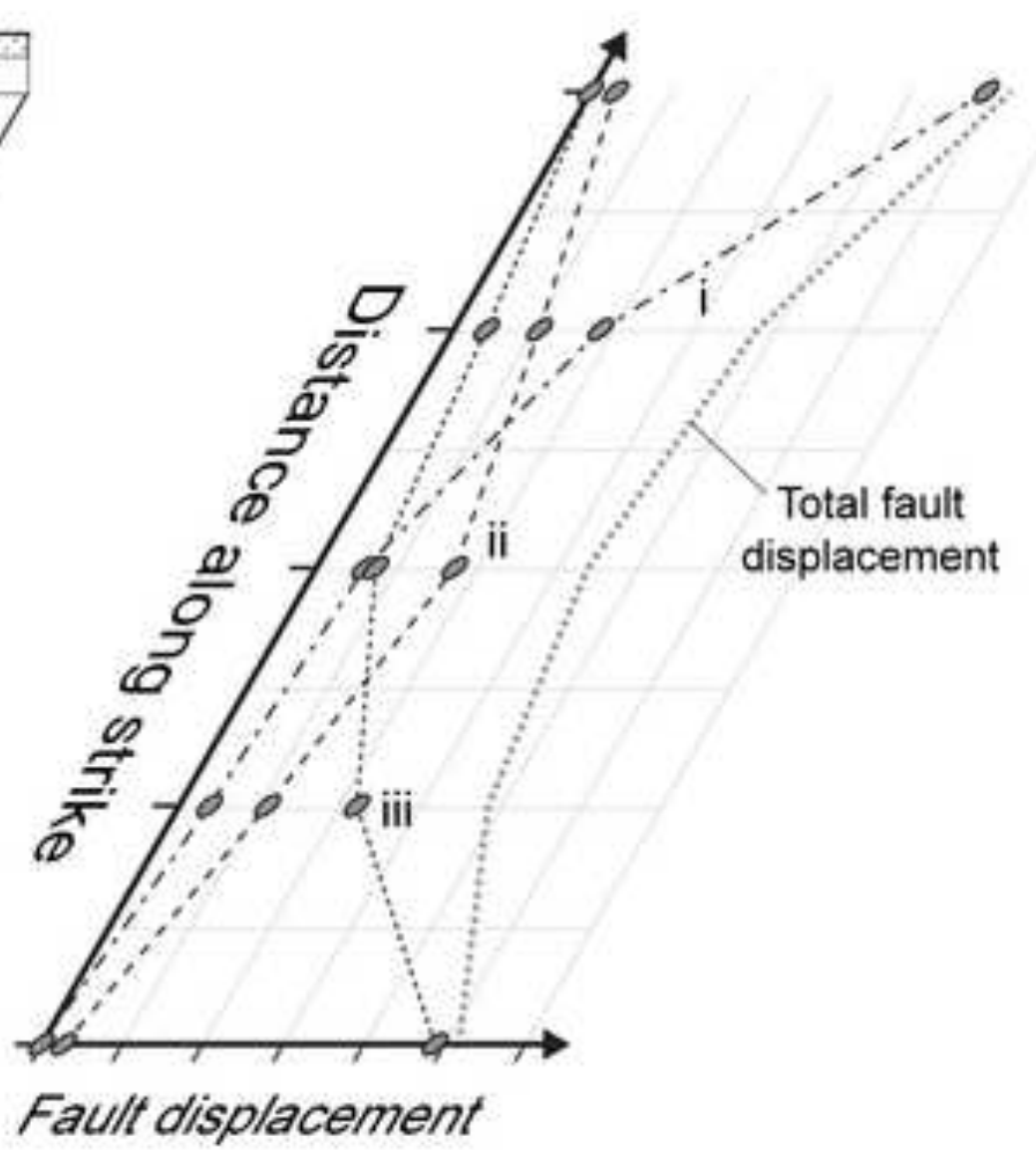


Click here to download high resolution image

a

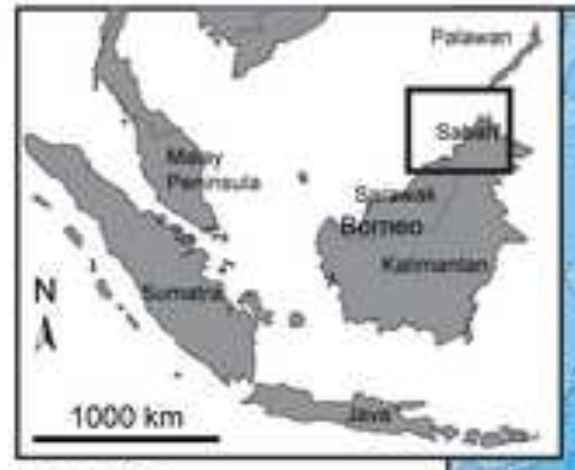

Legend:

Thrust Fault

$>$ Counter Regional Reverse Fault

Normal Regional Fault

C Counter Regional Normal Fault

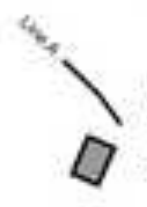

Regional 2D seismic line 3D seismic survey
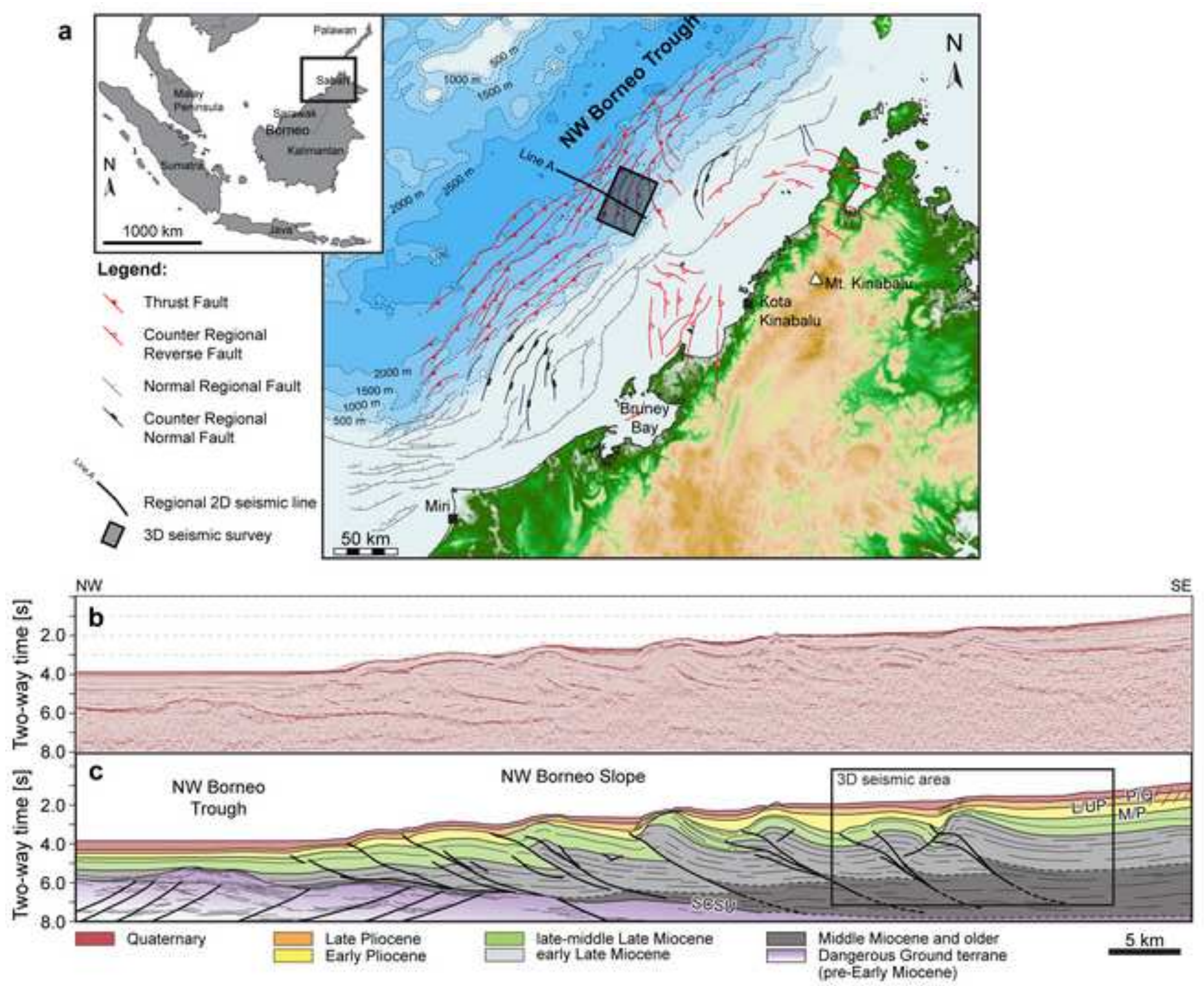
Click here to download high resolution image
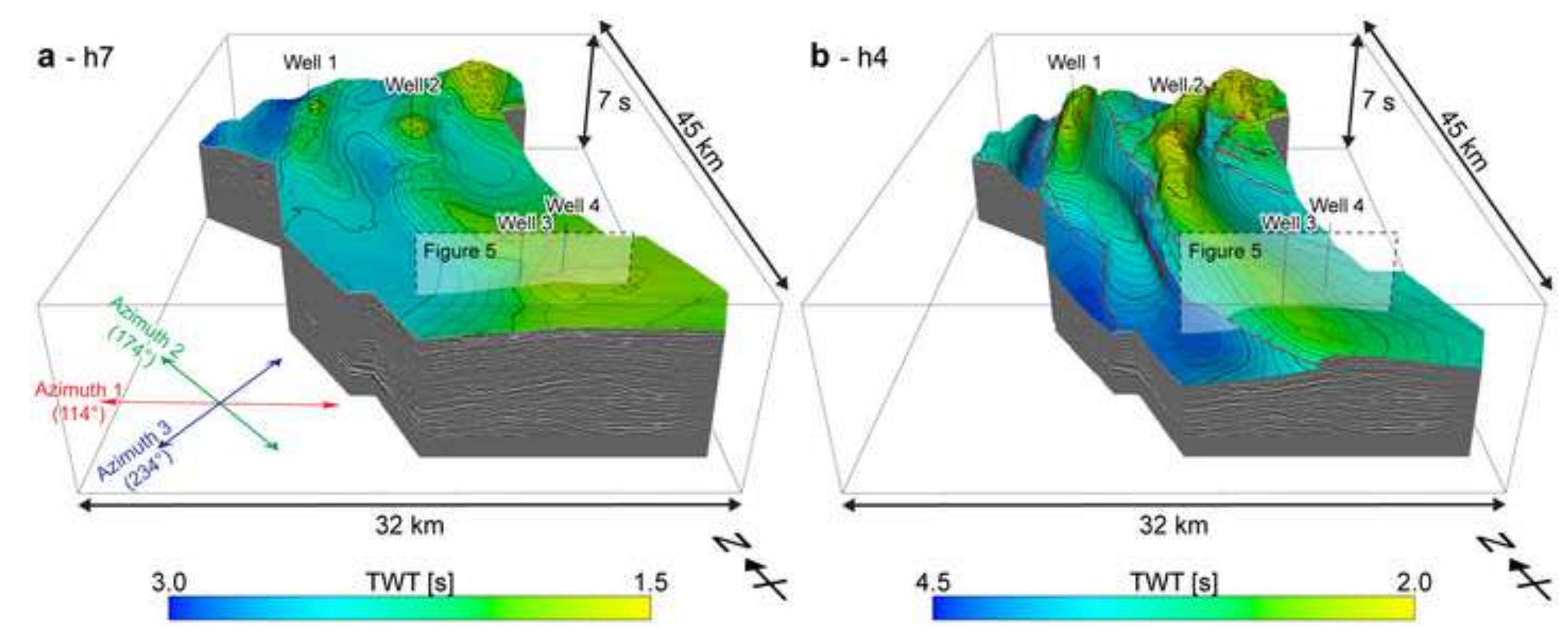

Click here to download high resolution image 
Click here to download high resolution image

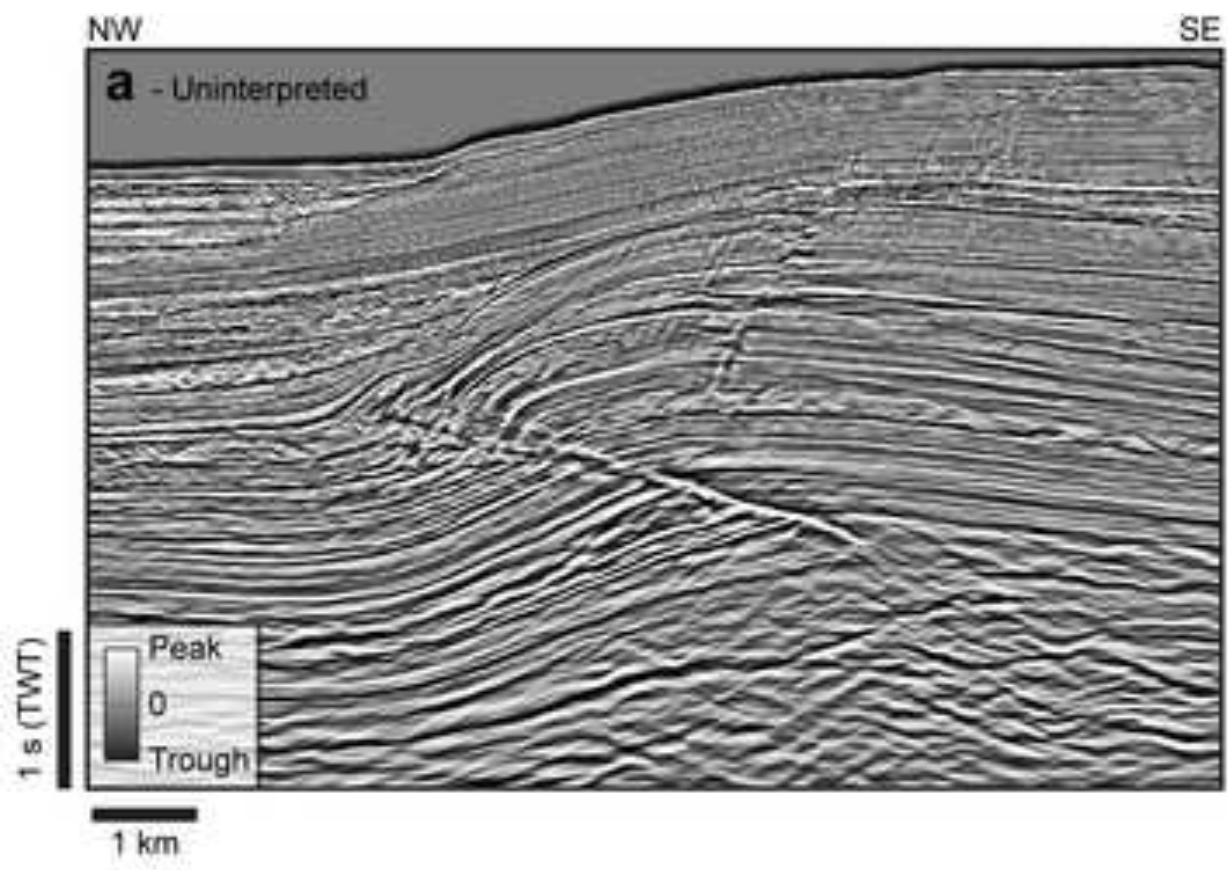

SE NW

Well 3

SE

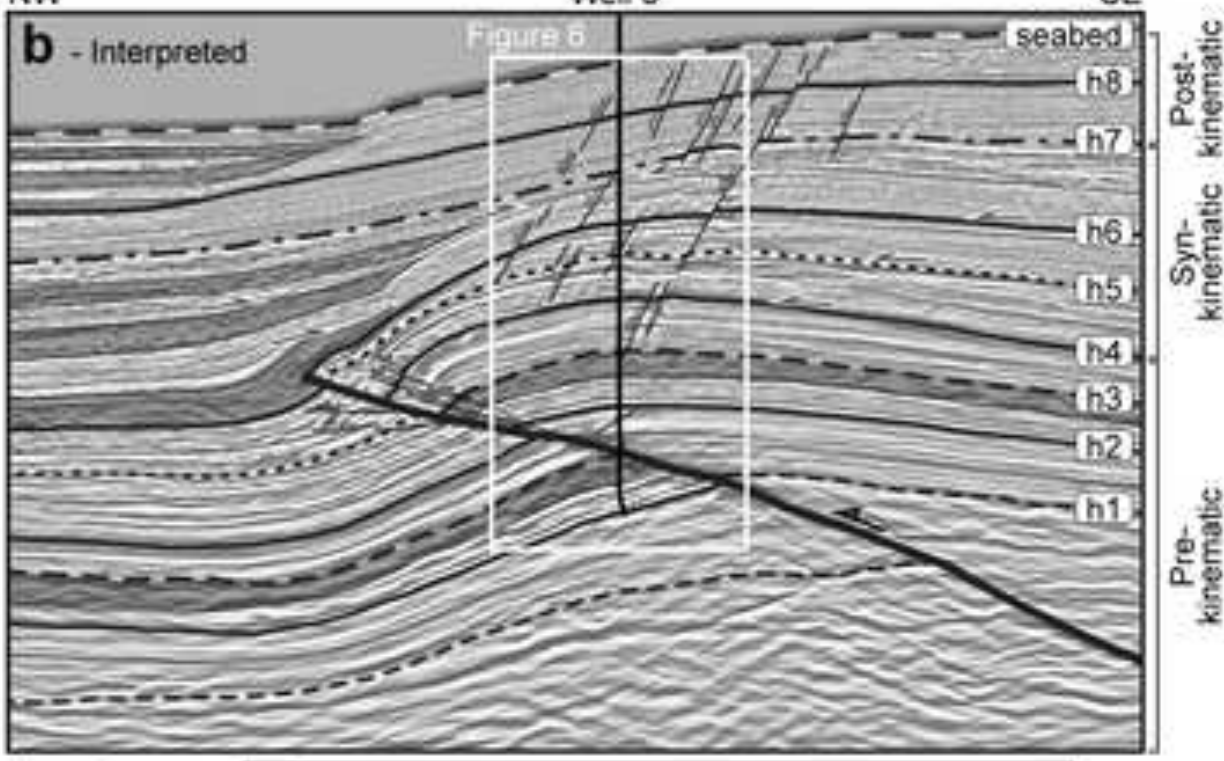

\begin{tabular}{|c|c|c|}
\hline $1 \mathrm{~km}$ & $\begin{array}{l}\text { Normal fault } \\
\text { Thrust fault }\end{array}$ & $\begin{array}{l}\text { Onlap pattern } \\
\rightleftharpoons \text { Mass Transport deposit }\end{array}$ \\
\hline
\end{tabular}


Click here to download high resolution image

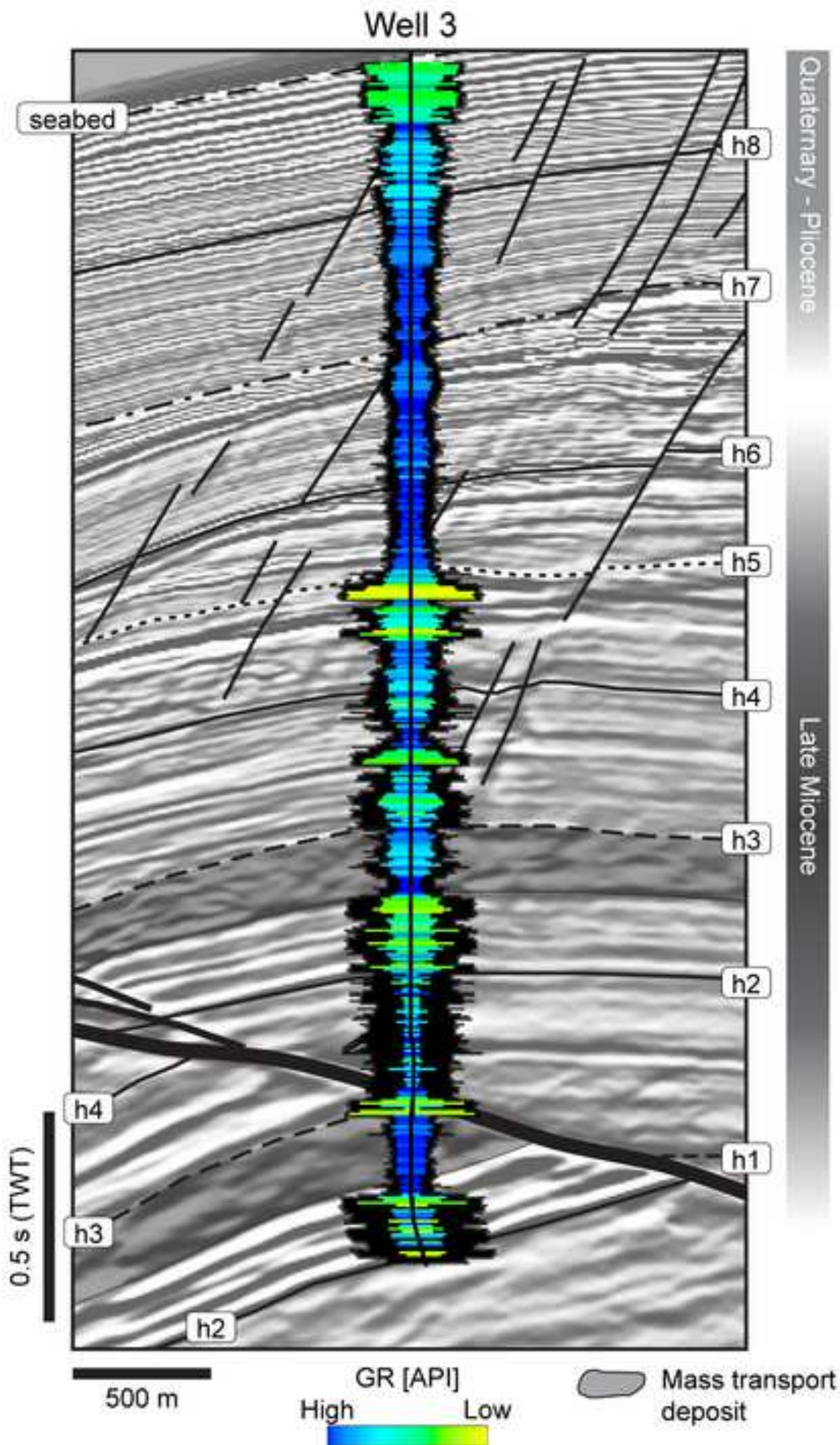



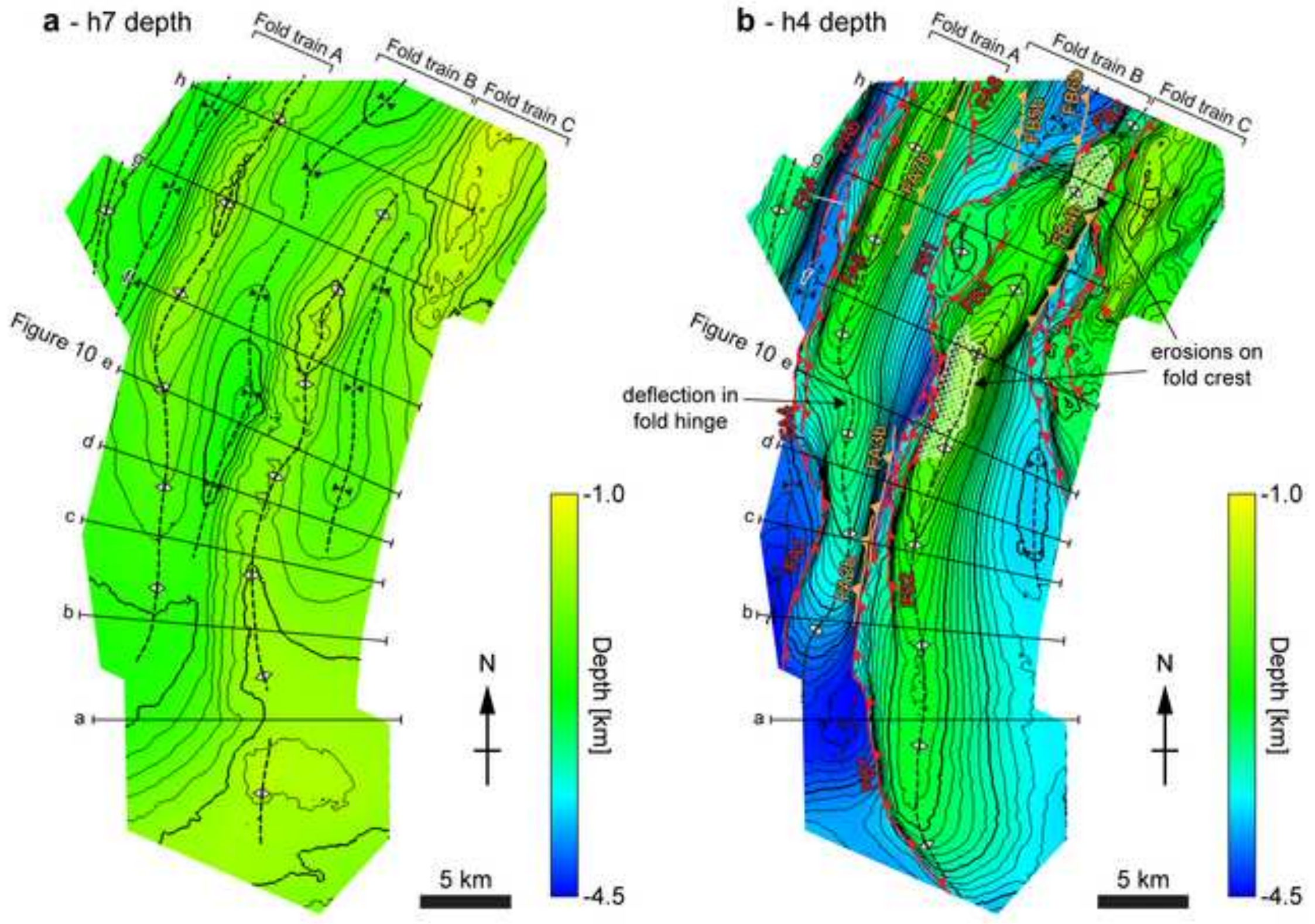


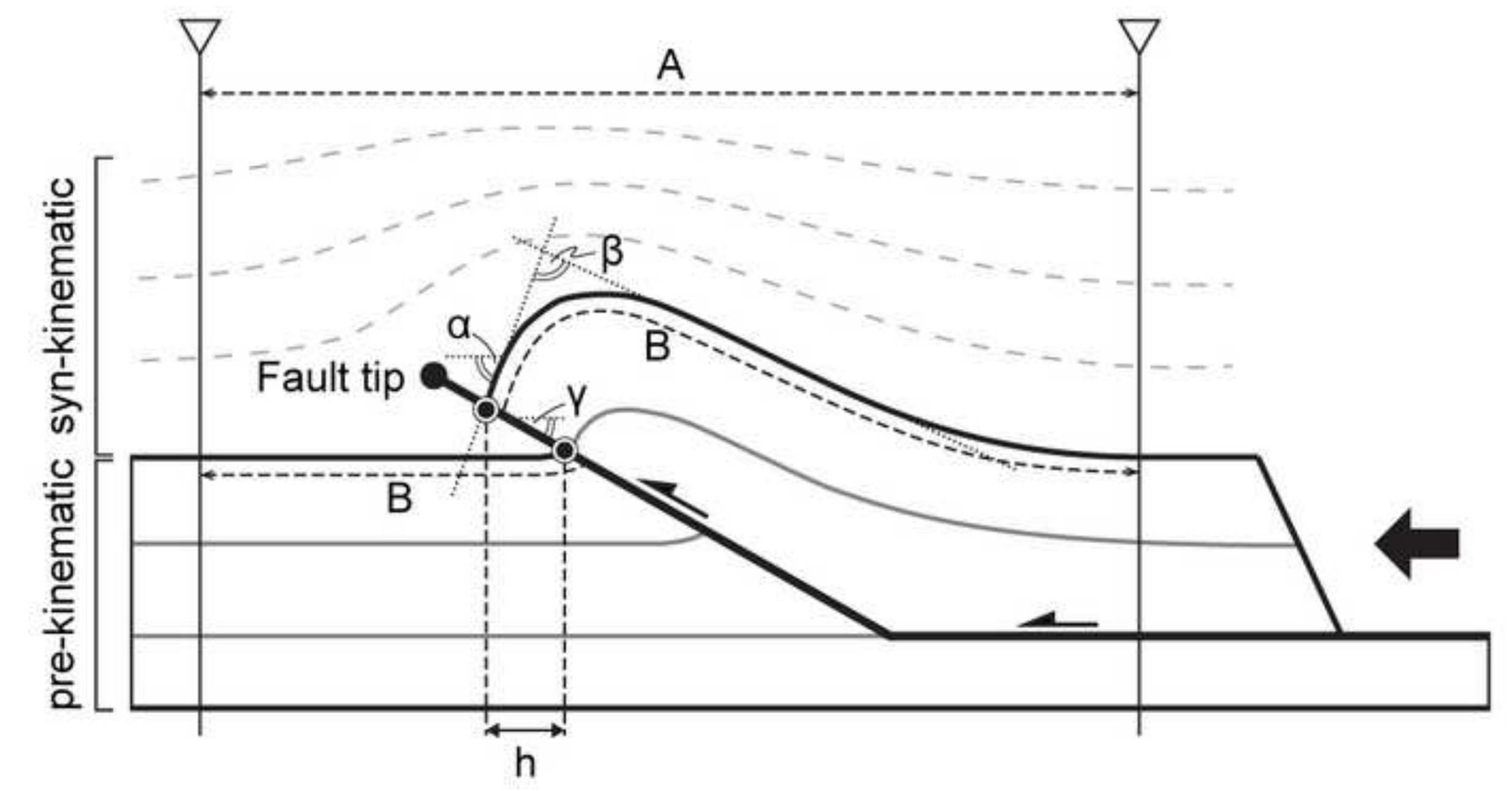

Click here to download high resolution image 


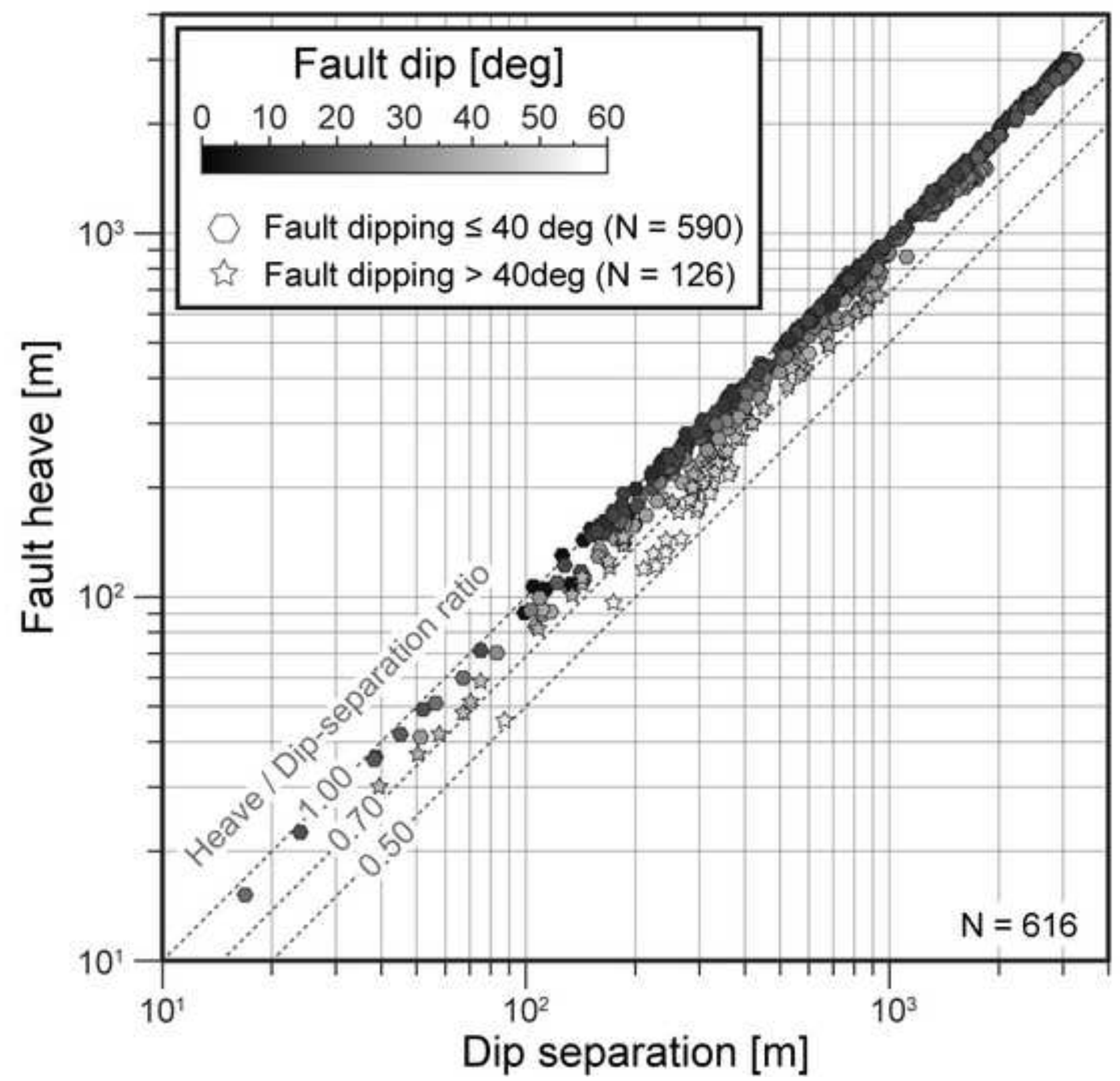




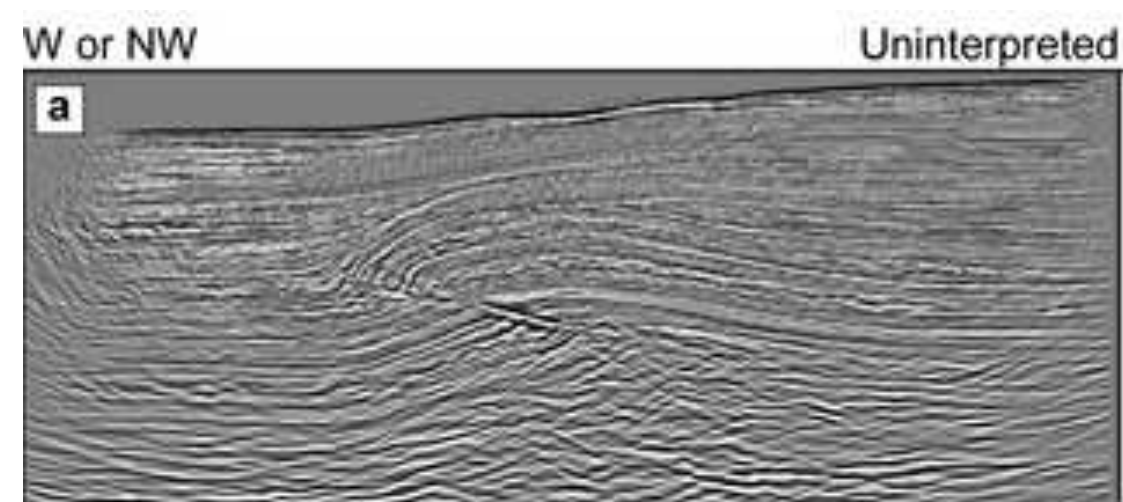

b
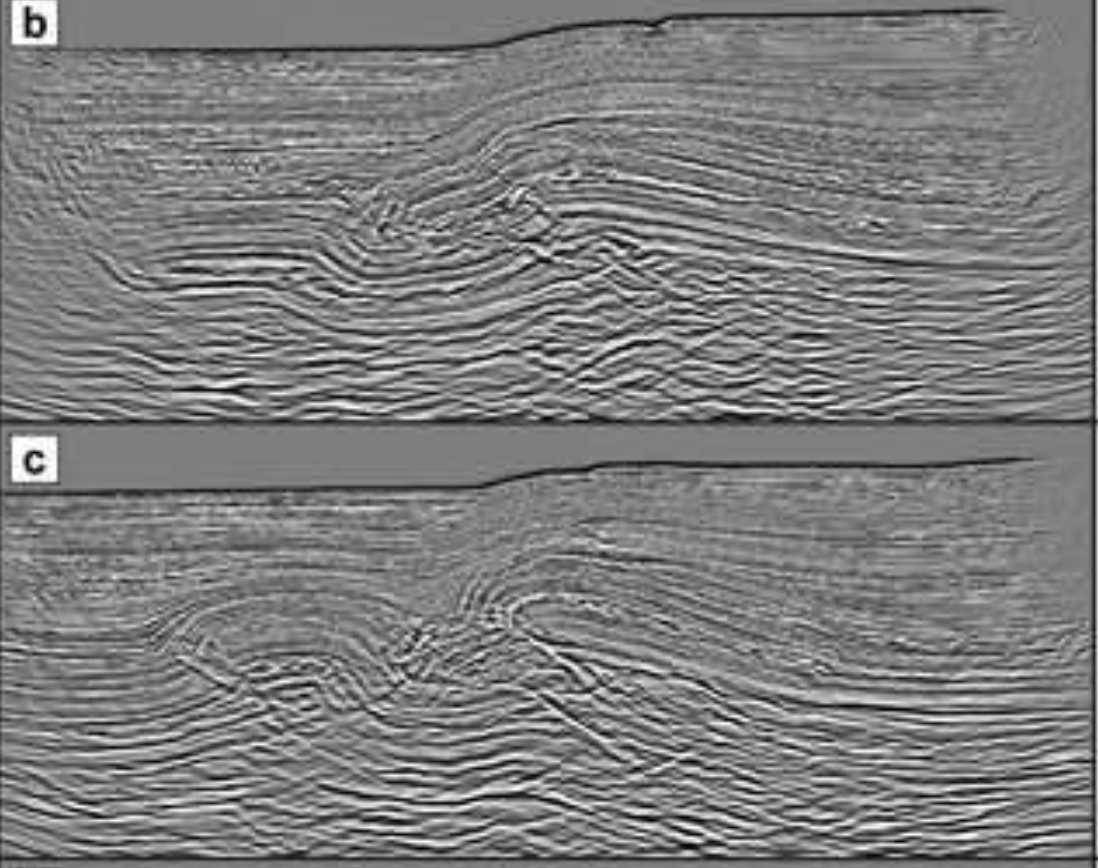

d

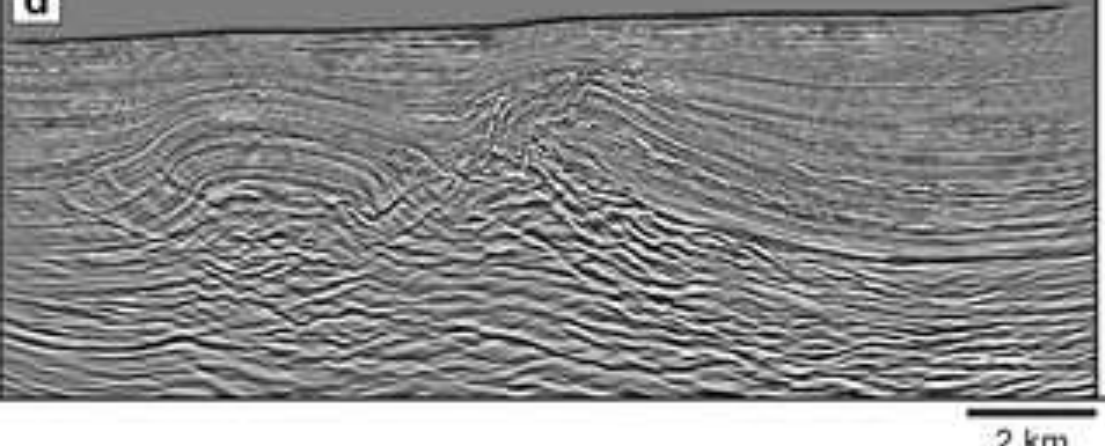

Interpreted

E or SE

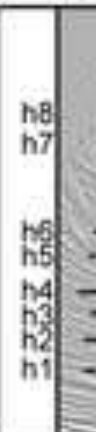

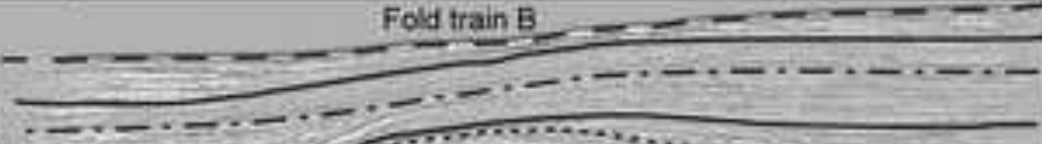
- Fold train B $\ldots-\cdots-\cdots-\cdots$

\section{FB1}
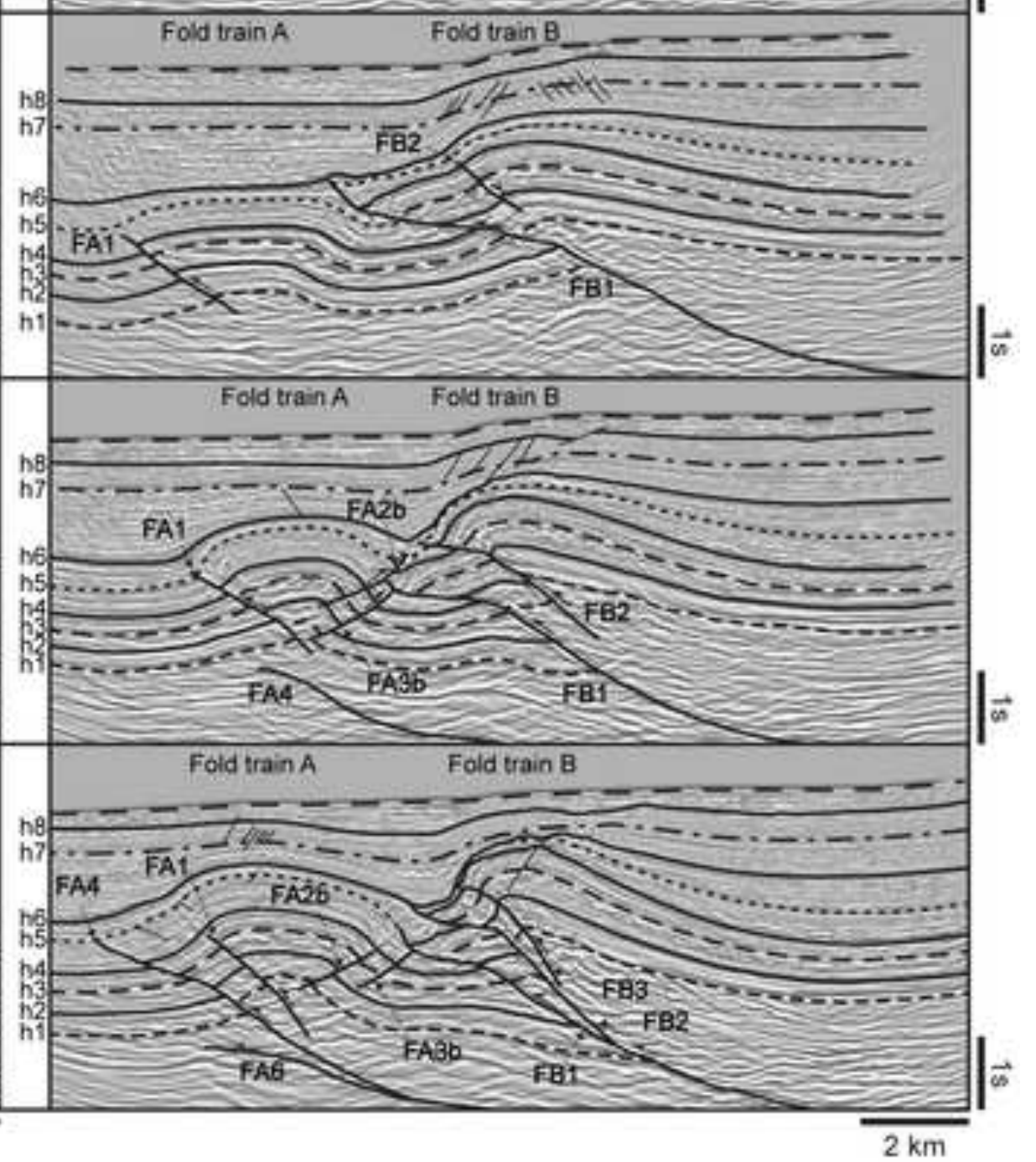


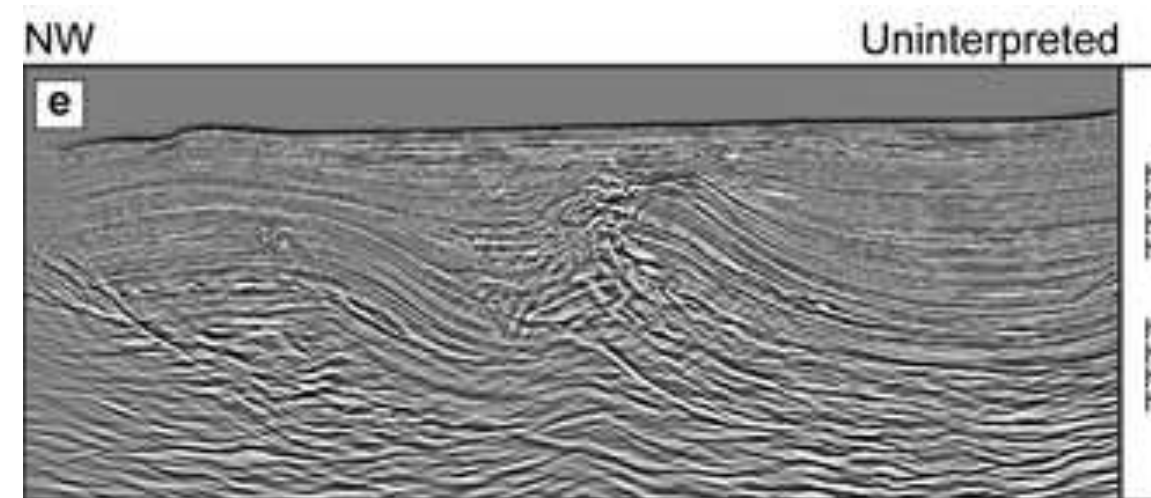

Interpreted
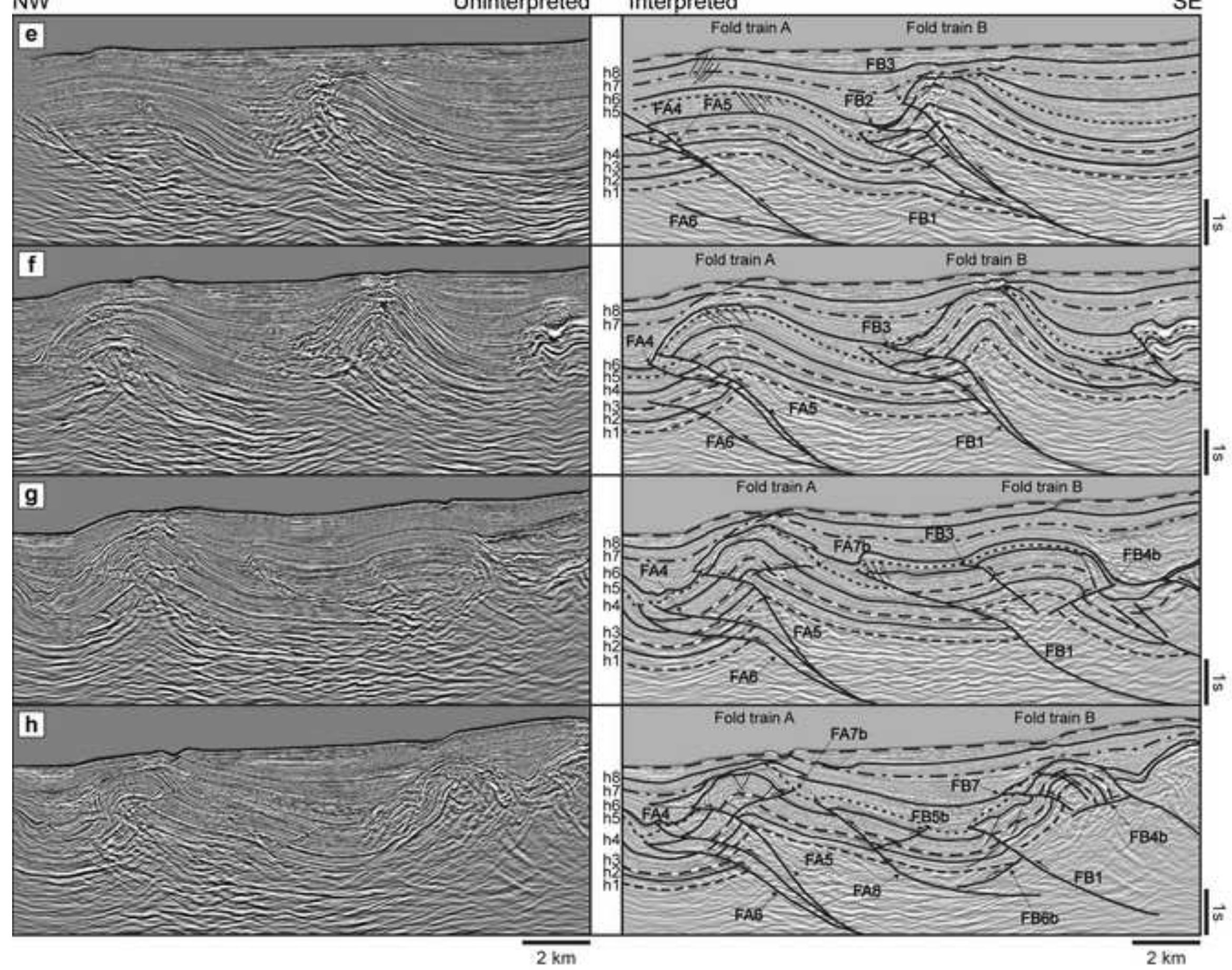


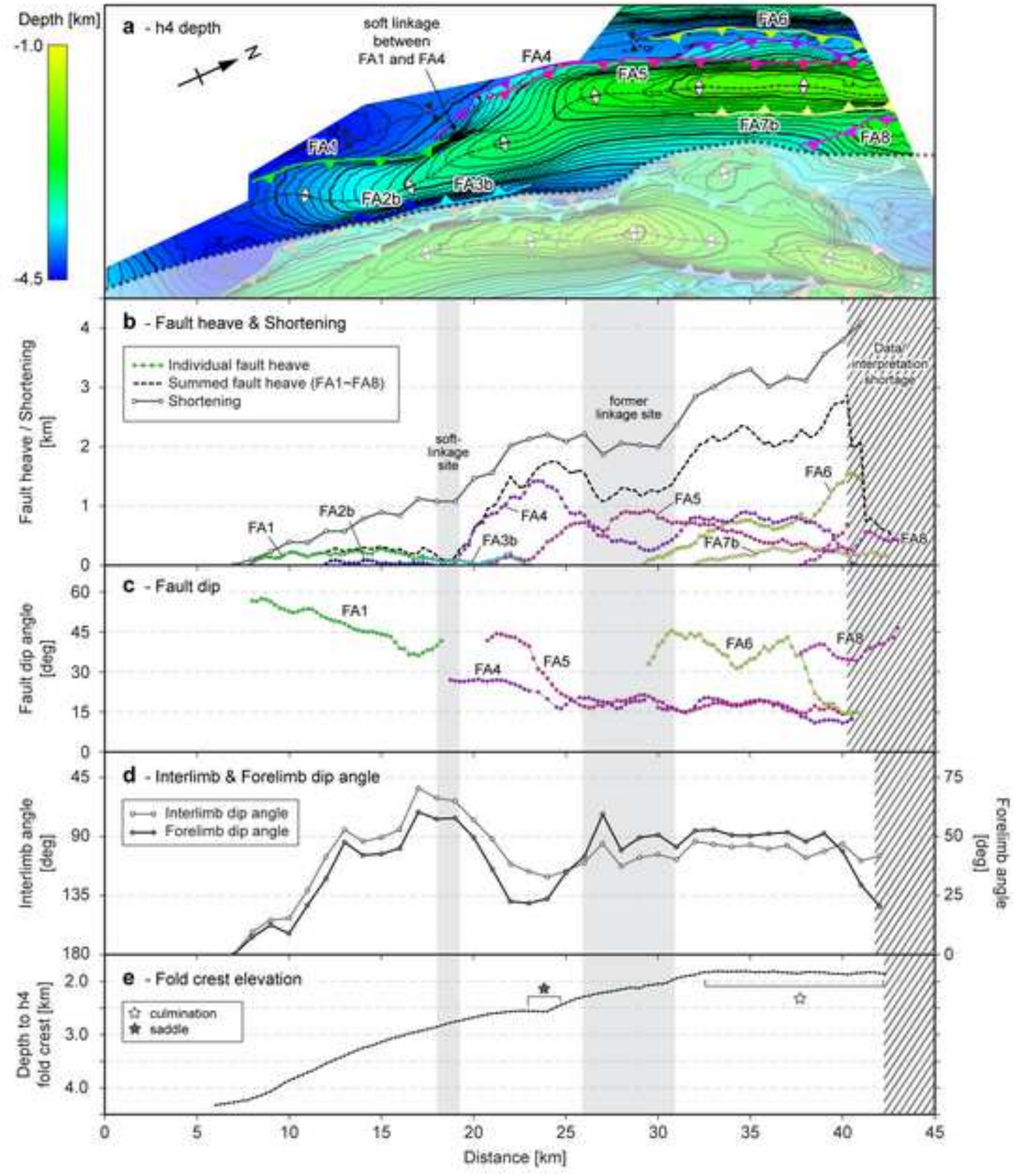




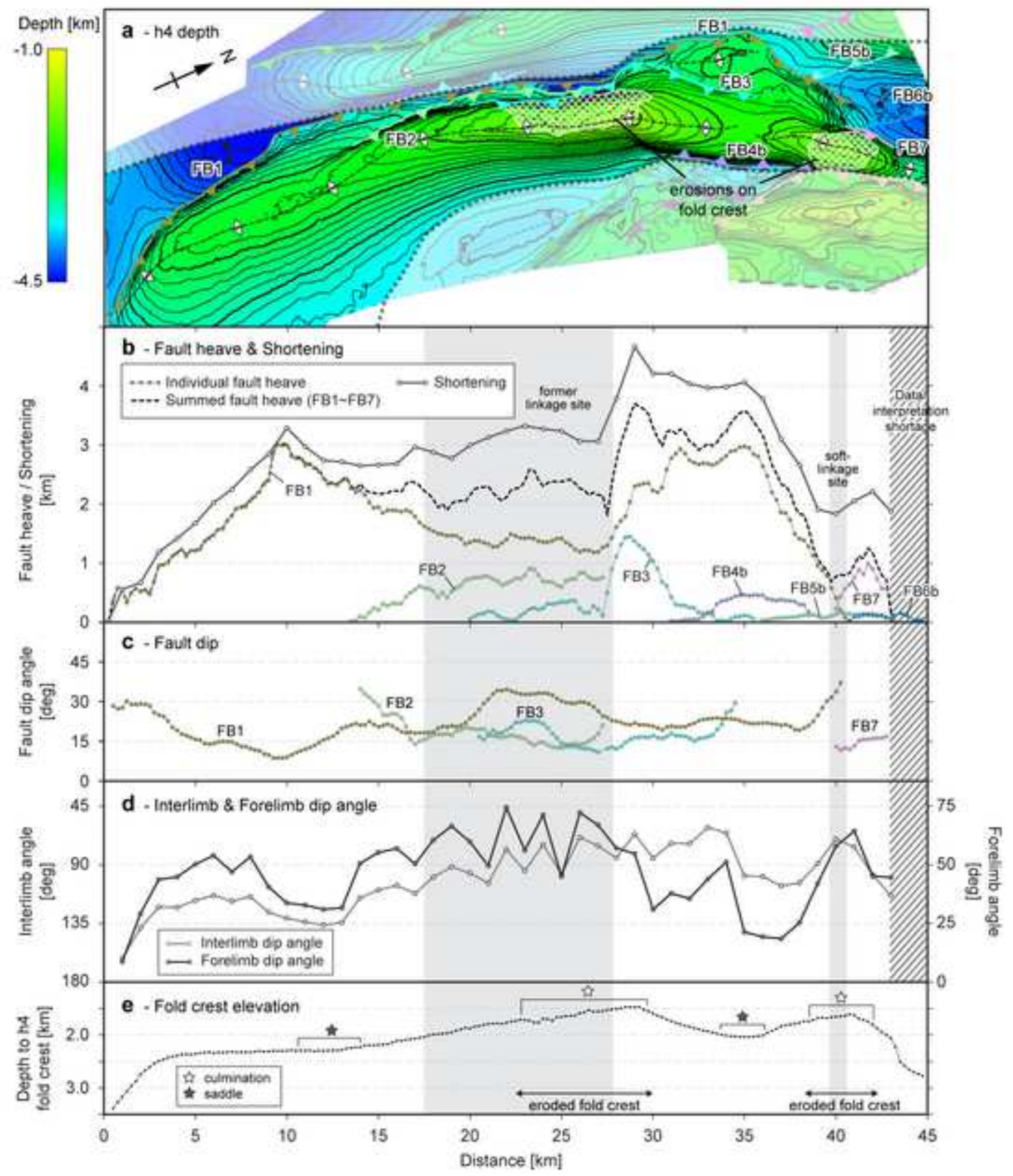



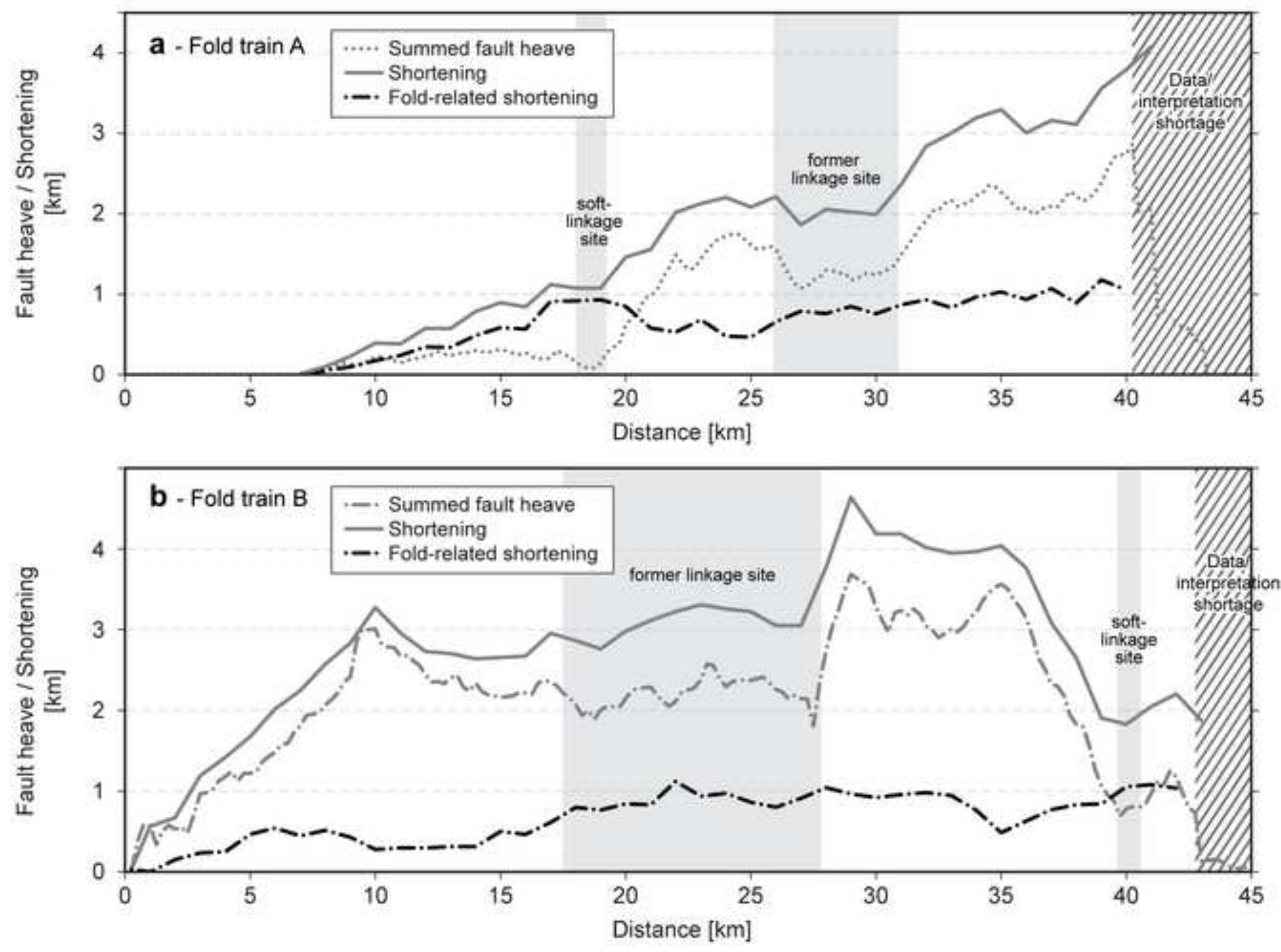
Click here to download high resolution image
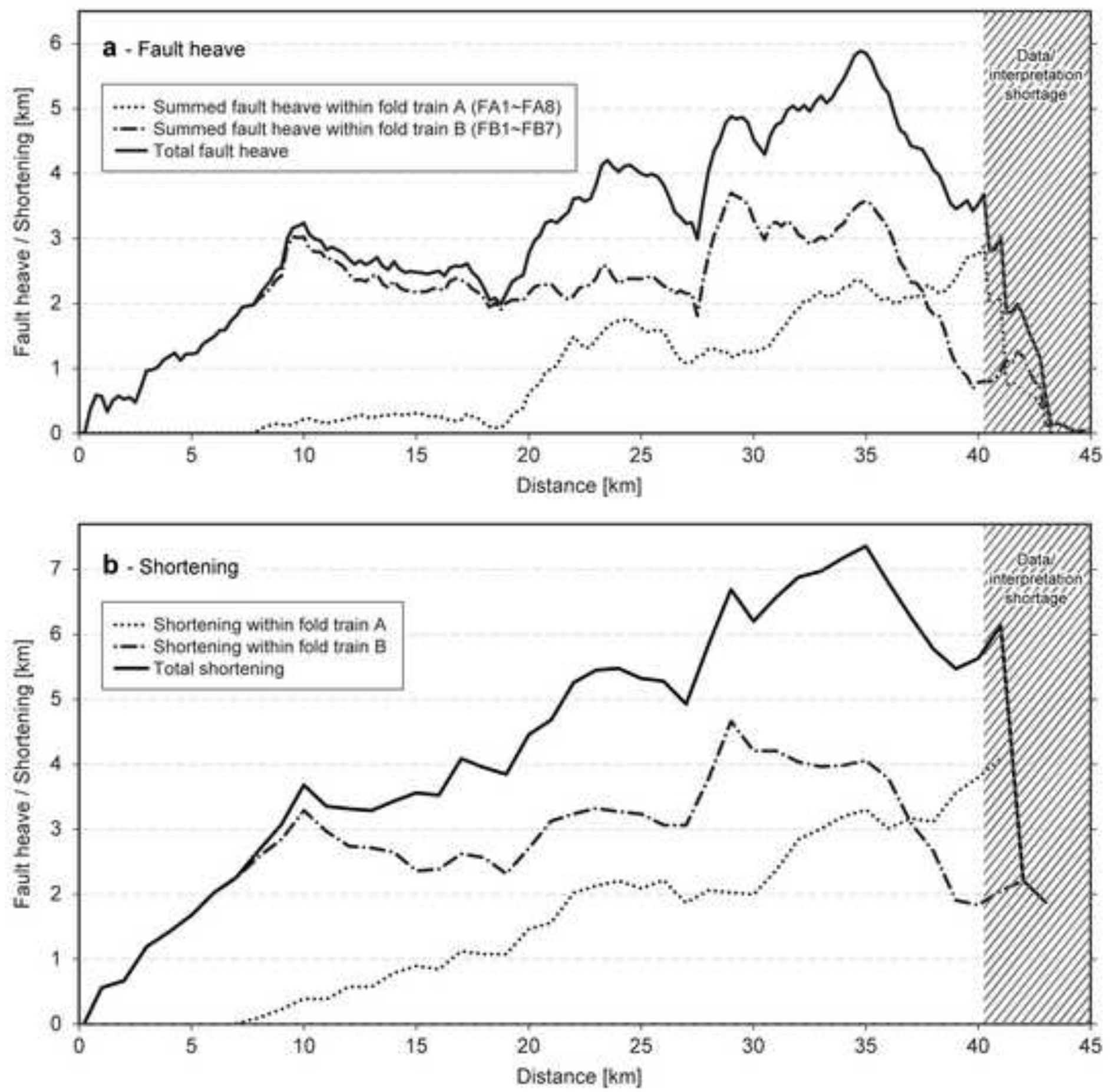


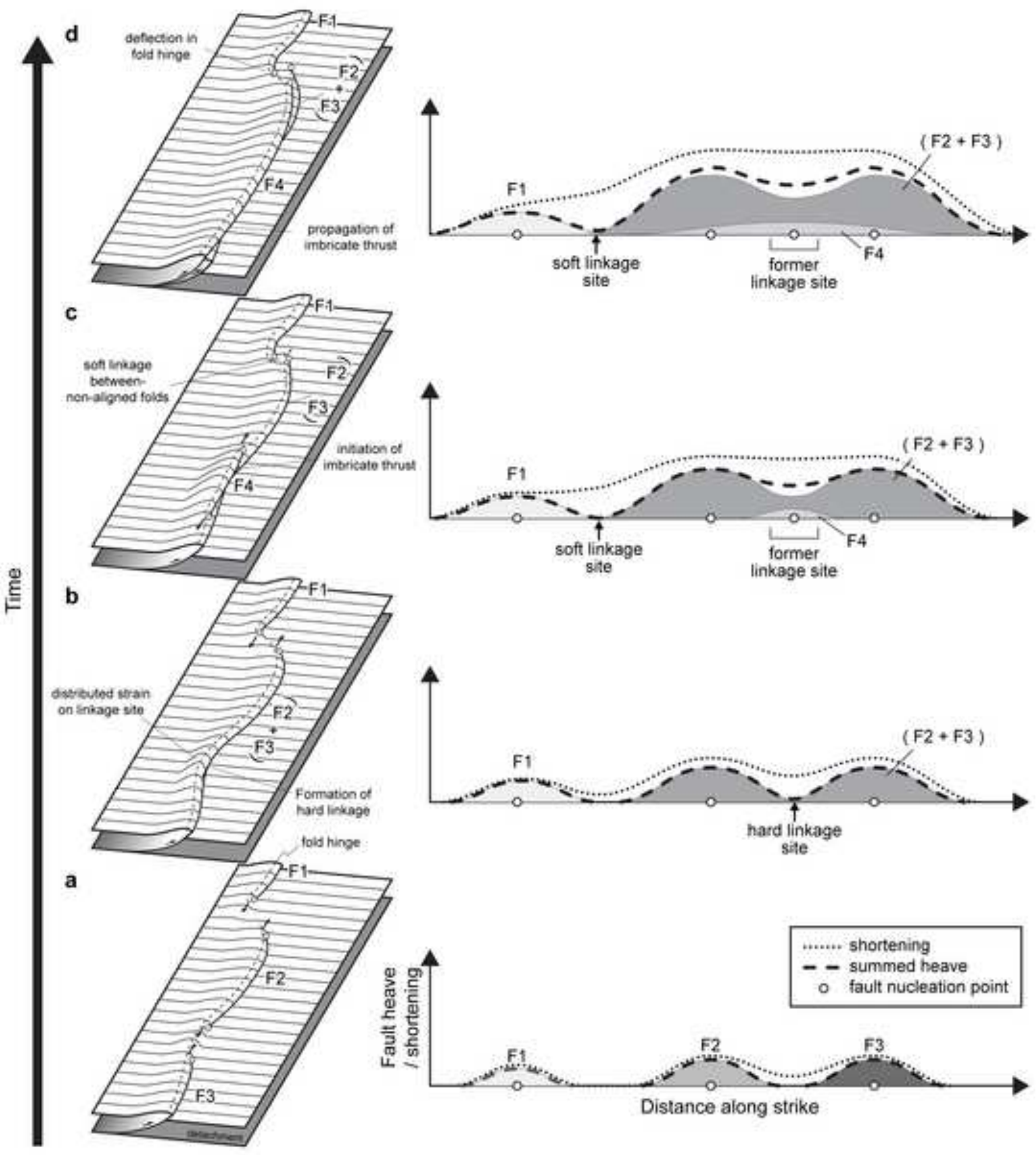

